\title{
Using E-Z Reader to model the effects of higher level language processing on eye movements during reading
}

\author{
Erik D. Reichle, Tessa Warren, ANd Kerry MCCONNELl \\ University of Pittsburgh, Pittsburgh, Pennsylvania
}

\begin{abstract}
Although computational models of eye-movement control during reading have been used to explain how saccadic programming, visual constraints, attention allocation, and lexical processing jointly affect eye movements during reading, these models have largely ignored the issue of how higher level, postlexical language processing affects eye movements. The present article shows how one of these models, E-Z Reader (Pollatsek, Reichle, \& Rayner, 2006c), can be augmented to redress this limitation. Simulations show that with a few simple assumptions, the model can account for the fact that effects of higher level language processing are not observed on eye movements when such processing is occurring without difficulty, but can capture the patterns of eye movements that are observed when such processing is slowed or disrupted.
\end{abstract}

Reading is arguably the most complex cognitive activity in which humans routinely engage (Huey, 1908; Rayner \& Pollatsek, 1989). To appreciate its complexity, consider what transpires in the mind of a reader during just a few seconds of reading (see, e.g., Gough, 1972): When the eyes move to a new location on the printed page, visual features from the input are propagated from the eyes to portions of the visual system that extract their shapes and locations in order to generate visual representations of both individual letters and words (McCandliss, Cohen, \& Dehaene, 2003). Some small number of these features are selected through attention (McConkie \& Rayner, 1975; Rayner, 1975) and then rapidly converted into nonvisual representations, including the orthographic and phonological codes that correspond to a word's spelling and pronunciation, respectively, and the codes that correspond to a word's meaning and syntactic category (see, e.g., Taft, 1991). At some point while this is happening, enough information will have accrued from the fixation to warrant moving the eyes to a new location. At this point, the oculomotor system uses the information about word boundaries available in peripheral vision to begin programming a saccade to move the eyes to another location. While this saccade is being programmed, the lexical information that has become available will be integrated with whatever syntactic and/or semantic information had been extracted from previously identified words to build a representation of the sentence (Frazier, 1998) and of whatever situation is being described by the larger text (Kintsch, 1988). And finally, while this integration is being completed, the systems involved in visual and lexical processing are directed toward the next unidentified word, causing both the eyes and attention to move down the line of text.

Of course, this description of the cognitive processes that occur during a short interval of reading is a gross oversimplification. For example, it says nothing about the functional characteristics of the individual processes (e.g., how long they take to complete, etc.), nor about the representations they operate on. It also ignores the fact that many of these processes are themselves dependent on even more basic or domain-general cognitive systems (e.g., working memory; Baddeley, 1986). Also, this description suggests that the cognitive processes involved in reading are executed in a strictly bottom-up manner, with the construction of the textual representation being entirely driven by the inflow of visual and lexical information. Evidence instead suggests that many of the cognitive processes involved in reading are highly interactive; for example, highly predictable words (e.g., function words) are often identified more rapidly than less predictable words because they are constrained by their semantic and/ or syntactic contexts (Balota, Pollatsek, \& Rayner, 1985; Ehrlich \& Rayner, 1981; Rayner, Ashby, Pollatsek, \& Reichle, 2004; Rayner \& Well, 1996). Finally, this description of what transpires in the mind of a reader also ignores the fact that the automatic coordination of so many interrelated processes is a skill usually acquired only after formal training and much practice. 
Over the past 100 years, a considerable amount has been learned about what happens in the minds of readers, much of it by studying eye movements (Rayner, 1978, 1998; Rayner \& Pollatsek, 1989). Because printed text—in contrast to spoken language - is arranged along a spatial dimension (e.g., in English, lines of text proceed from left to right and from top to bottom), one can make inferences about the cognitive processes that occur during reading, by measuring when and where readers move their eyes (Rayner, 1979). The logic of this method is predicated on the simple assumption that where a reader is looking at any point in time reflects, at least to some degree, whatever is going on in his or her mind at that time (Just \& Carpenter, 1980). Although a strong version of this assumption is incorrect (e.g., readers often partially process upcoming words before they are actually fixated; Balota et al., 1985; Rayner, 1975), a weaker form is a reasonable approximation, as evidenced by the fact that a large variety of visual and linguistic variables have been shown to influence readers' eye movements (for a review, see Rayner, 1998).

In fact, eye-movement experiments have taught us so much about the cognitive processes involved in reading that the last decade has witnessed the development of a number of new computational models of readers' eye movements (Engbert, Nuthmann, Richter, \& Kliegl, 2005; Feng, 2006; McDonald, Carpenter, \& Shillcock, 2005; Reichle, Pollatsek, Fisher, \& Rayner, 1998; Reilly \& Radach, 2006; Yang, 2006; for an overview of several of these models, see the 2006 special issue of Cognitive Systems Research). These models were developed to describe and explain how primary constraints related to saccadic programming (e.g., saccadic error), visual processing (e.g., limited retinal acuity), attention allocation (e.g., whether attention is allocated to one or more than one word at a time), and the identification of words affect where and how long readers direct their gaze during reading. Although these models often make different assumptions about how these various constraints determine the moment-to-moment movement of a reader's eyes, each is able to reproduce a significant number of eye-movement behaviors observed during reading and to describe how these behaviors are influenced by various oculomotor, visual, and/or lexical constraints. These models share a common limitation, however, in that they have said very little or nothing about how higher level language processing influences readers' eye movements.

Although we acknowledge that the strategy of building models that explain only the effects of low-level processes (e.g., word identification) but that ignore higher level, postlexical influences has been successful in advancing the field, we believe that this strategy has incurred at least two hidden costs. The first is that by focusing exclusively on low-level variables, experimenters have failed to use these models to their full potential. For example, models that more accurately describe how all aspects of language processing affect eye movements would hold tremendous potential as analytical frameworks for evaluating existing theoretical assumptions about language processing (e.g., just as one current model has been used to test the adequacy of various accounts of lexical ambiguity resolution; Reichle, Pollatsek, \& Rayner, 2007). Similarly, such models will be extremely useful for generating novel predictions that can then be tested by new empirical research (see, e.g., Pollatsek, Juhasz, Reichle, Machacek, \& Rayner, 2008).

The second cost is more directly related to the models themselves: Until now, most of the debate about which of the models more accurately describes the processes that guide readers' eye movements has focused on very low-level phenomena, such as the degree to which the models successfully explain fixation landing-site distributions (see Reichle, Rayner, \& Pollatsek, 1999; Reilly \& O'Regan, 1998). Although such phenomena are important, the models have not been evaluated on their potential capacity (or lack thereof) to explain the many phenomena related to higher level language processing that have also been well documented in the literature and that are also important for our understanding of reading (for a review, see Clifton, Staub, \& Rayner, 2007). Higher level language processing provides a second basis for comparing models of eye-movement control - one that may be more diagnostic for evaluating the theoretical adequacy of existing and future models.

For these reasons, we believe that it is time to attempt to model how higher level language processing influences the patterns of eye movements that are observed during reading. The remainder of this article will describe our attempt to do this. We use the most recent version of the E-Z Reader model of eye-movement control in reading (Pollatsek, Reichle, \& Rayner, 2006c; Reichle, Pollatsek, \& Rayner, 2006) as a framework for embedding our assumptions about how higher level language processing interacts with the other systems known to affect readers' eye movements. The version of the E-Z Reader model that will be described in this article (E-Z Reader 10$)$ provides a preliminary account of how the time course of postlexical language processing and its completion influence attention and lexical processing, and thereby affect eye movements during reading. Before introducing this version of the model and showing how it describes such effects, however, we will first provide a brief overview of the model's immediate predecessor, E-Z Reader 9. (For a complete description of E-Z Reader 9, see Pollatsek et al., 2006c; Reichle et al., 2006.)

\section{E-Z READER}

Figure $1 \mathrm{~A}$ is a schematic diagram of E-Z Reader 9. As the figure shows, the model describes how a preattentive stage of visual processing, the allocation of attention, word identification, and the operating characteristics of the oculomotor system affect when and where readers move their eyes during reading. The figure also illustrates the two core assumptions of the model: (1) that the completion of an early stage of lexical processing on word $n$, called the familiarity check, or $\mathrm{L}_{1}$, is the "trigger" that causes the oculomotor system to begin programming 
A

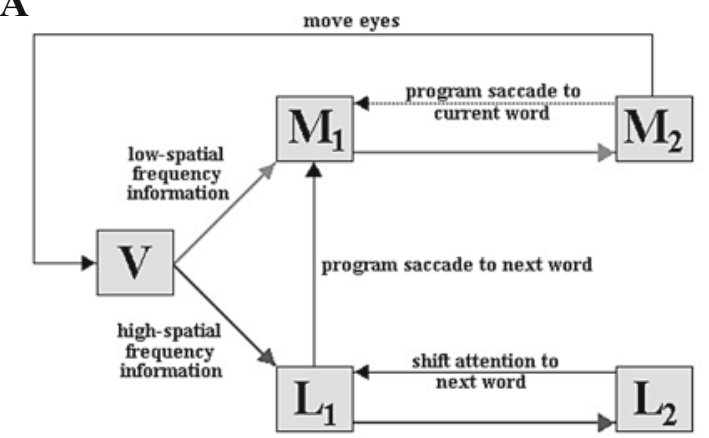

B

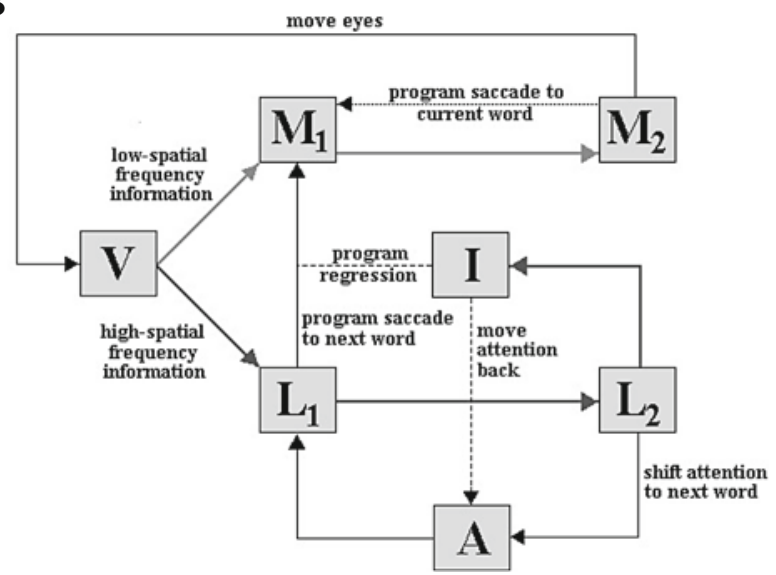

Figure 1. Panel A: Schematic diagram of E-Z Reader 9 (Pollatsek, Reichle, \& Rayner, 2006c). Panel B: Schematic diagram of E-Z Reader 10, with its assumption about attention (A) and postlexical integration (I). The thick arrows indicate how information flows between the model's components, the thin solid arrows indicate obligatory transitions between components, and the thin dotted arrows indicate probabilistic transitions. See the text for detailed descriptions of both versions of the model.

a saccade to move the eyes from word $n$ to word $n+1$; and (2) that the subsequent completion of a second stage of lexical processing on word $n$, called the completion of lexical access, or $\mathrm{L}_{2}$, causes attention to shift from word $n$ to word $n+1$. Thus, the programming of saccades is decoupled from the shifting of attention, which is allocated serially to only a single word at a time.

According to the assumptions of the model, there is an early, preattentive stage of visual processing (labeled "V" in Figure 1), during which the visual features on the printed page are propagated from the retina to the brain. The time that is needed to do this in the model, $t(\mathrm{~V})$, is assumed to equal $50 \mathrm{msec}$. This time reflects recent physiological research showing that the eye-to-brain lag is approximately 50 msec (Clark, Fan, \& Hillyard, 1995; Foxe \& Simpson, 2002; Mouchetant-Rostaing, Giard, Bentin, Aguera, \& Pernier, 2000; VanRullen \& Thorpe, 2001). The low-spatial-frequency visual information that is extracted during this stage of processing (e.g., the blank spaces that demarcate individual words) is used by the oculomotor system to select saccade targets. A small subset of the high-spatial-frequency information (e.g., the features that are necessary for identifying individual letters) is also selected via attention to be used by the word-identification system for further lexical processing.

As already mentioned, the first stage of lexical processing in the model is $\mathrm{L}_{1}$, the familiarity check. The duration of $\mathrm{L}_{1}$ on word $n$ during any given Monte Carlo simulation run, $t\left(\mathrm{~L}_{1}\right)$, is determined by sampling a random deviate from a gamma distribution with a mean specified by Equation 1, below $\left(S D=0.22 \mathrm{~L}_{1}\right)$. As Equation 1 shows, the duration of $\mathrm{L}_{1}$ is a function of the natural logarithm of word $n$ 's frequency of occurrence in printed text, as estimated by using the norms of Francis and Kučera (1982), and its local, within-sentence predictability, as estimated by using cloze-task norms (i.e., the proportion of subjects who, when given all of the words up through word $n-1$, are able to correctly guess the identity of word $n) .{ }^{1}$ Note that in the model, word $n$ can sometimes (with a probability, $p$, equal to the word's predictability) be "guessed" from its preceding sentence context. When this happens, the duration of $\mathrm{L}_{1}$ for word $n$ is set equal to $0 \mathrm{msec}$ (see the upper branch of Equation 1). This assumption is consistent with observations that in eye-movement experiments where only the fixated word is displayed (i.e., all of the other words are replaced by Xs), readers sometimes do not fixate short, highly predictable words, such as the word the (Rayner, Well, Pollatsek, \& Bertera, 1982). However, for most words, the duration of $\mathrm{L}_{1}$ (in milliseconds) is determined by the lower branch of Equation 1, where $\alpha_{1}(122), \alpha_{2}(4)$, and $\alpha_{3}(10)$ are free parameters that determine the rate of lexical processing. Words that are more common (frequent) are therefore processed more rapidly and are the recipients of fewer and/or shorter fixations than are less common words; this is consistent with empirical results (Inhoff \& Rayner, 1986; Rayner, 1977; Rayner \& Duffy, 1986; Schilling, Rayner, \& Chumbley, 1998). Similarly, words that are predictable from their sentence context are processed more rapidly and are the recipients of fewer and/or shorter fixations than are less predictable words, which is also consistent with empirical results (Balota et al., 1985; Ehrlich \& Rayner, 1981; Rayner et al., 2004; Rayner \& Well, 1996).

Another important constraint in the model is related to limited visual acuity: Words that are farther from the center of vision (i.e., from the fovea) and/or are longer require more time to process than do words near the fovea and/or shorter words (Rayner \& Morrison, 1981), because the high-resolution vision that is necessary to perceive the fine details that comprise letters and words decreases rapidly from the fovea to peripheral vision. The relationship between word $n$ 's length, the duration of $\mathrm{L}_{1}$, and visual acuity is thus specified by Equation 2, where $t\left(\mathrm{~L}_{1}\right)^{\prime}$ is the duration of $t\left(\mathrm{~L}_{1}\right)$, as modulated by visual acuity. In Equa-

$$
\mathrm{L}_{1}= \begin{cases}0 & \text { if } p \leq \text { predictability }_{n} \\ \alpha_{1}-\alpha_{2} \ln \left(\text { frequency }_{n}\right)-\alpha_{3} \text { predictability }_{n} & \text { if } p>\text { predictability }_{n}\end{cases}
$$


tion $2, \varepsilon(1.15)$ is a free parameter that controls the degree to which visual acuity slows lexical processing, fixation is the location of the character space being fixated, letter is the location of the central letter of the word being processed, and $N$ is the number of letters in word $n$. The exponent in Equation 2 thus reflects the mean disparity between each of the letters in the word being processed and the fixation location from where the word is being processed.

$$
t\left(\mathrm{~L}_{1}\right)^{\prime}=t\left(\mathrm{~L}_{1}\right) \varepsilon^{\sum \mid \text { fixation - letter } / / N}
$$

The second stage of lexical processing in the model is $\mathrm{L}_{2}$, the completion of lexical access and the activation of word $n$ 's meaning. The duration of $\mathrm{L}_{2}, t\left(\mathrm{~L}_{2}\right)$, is also sampled from a gamma distribution, with a mean specified by Equation $3\left(S D=0.22 \mathrm{~L}_{2}\right)$. Note that according to Equation 3, $\mathrm{L}_{2}$ is a fixed proportion of the duration of $\mathrm{L}_{1}$ (as specified by the lower branch of Equation 1) prior to being modulated by visual acuity. The free parameter $\Delta(.5)$ specifies this proportion. The rationale for these assumptions is that this later stage of lexical processing corresponds to the process of accessing word $n$ 's meaning (and therefore requires some nonzero amount of time to complete) and involves the processing of nonvisual codes (and hence is not affected by visual acuity or word length).

$$
t\left(\mathrm{~L}_{2}\right)=\mathrm{L}_{1} \Delta
$$

All of the remaining model assumptions are related to the programming and execution of saccades. They can be briefly summarized as follows (see Figure 1A; see Pollatsek et al., 2006c, for an in-depth discussion of these assumptions). First, saccades are programmed in two stages: an early, labile stage $\left(\mathrm{M}_{1}\right)$ that can be canceled by the initiation of subsequent saccadic programs, followed by a nonlabile stage $\left(\mathrm{M}_{2}\right)$ that is not subject to cancellation. The durations of these two programming stages, $t\left(\mathrm{M}_{1}\right)$ and $t\left(\mathrm{M}_{2}\right)$, are random deviates sampled from gamma distributions $(M=100 \mathrm{msec}, S D=0.22 ; M=25 \mathrm{msec}, S D=$ 0.22 , respectively).

Second, saccades are always directed toward the centers of words, but, because of both systematic and random motor error, they often miss their intended targets. Equations 4 through 6 specify the precise manner in which saccades are executed in the model. In Equation 4, the length of the saccade that is executed (in character spaces) is the sum of three terms: (1) the length of the saccade that is actually being programmed; (2) a systematic error component, as specified by Equation 5; and (3) a random error component, as specified by Equation 6. The systematic motor error causes short/long saccades to over-/ undershoot their intended targets by some amount, with the strength of this bias being modulated by the saccade launch-site fixation duration. In Equation 5, the free parameter $\Psi$ (seven characters) defines the saccade length bias, and two other free parameters, $\Omega_{1}$ (7.3) and $\Omega_{2}$ (3), determine how the strength of this bias is modulated by the launch-site fixation duration. The random error component is sampled from a Gaussian having a mean equal to 0 and a standard deviation that increases with the programmed saccade length. As indicated by Equation 6, the degree to which this standard deviation increases with saccade length is determined by two free parameters: $\eta_{1}(0.5)$ and $\eta_{2}(0.15)$. The time required for executing the actual saccade, $t(S)$, is set equal to a fixed value of $25 \mathrm{msec}$.

$$
\begin{aligned}
\text { saccade }= & \text { programmed saccade length } \\
& + \text { systematic error }+ \text { random error }
\end{aligned}
$$

systematic error $=(\Psi-$ programmed saccade length $)$

$$
\cdot\left\{\left[\Omega_{1}-\ln (\text { fixation duration) }] / \Omega_{2}\right\}\right.
$$

random error

$\operatorname{Gaussian}\left(0, \eta_{1}+\eta_{2} *\right.$ programmed saccade length)

The final model assumption about saccades is related to refixations: When the eyes move to a new word, a saccadic program to move the eyes to a second (perhaps better) viewing location is initiated after some delay, with a probability that increases with the saccadic error, or the distance between the center of the word being fixated (i.e., the intended saccade target) and the actual fixation location. The length of this delay, $t(\mathrm{R})$, is sampled from a gamma distribution with a mean of $\mathrm{R}=117 \mathrm{msec}(S D=$ $0.22 \mathrm{R}$ ). Equation 7 specifies how the probability of making a refixation increases as a function of saccadic error, with one free parameter, $\lambda(0.09)$, modulating the strength of this relationship.

Prob. refixation $=$

$$
\text { |center of word }- \text { initial fixation location } \mid \lambda
$$

These assumptions about saccade programming and execution are sufficient for the model to account for the finding that fixation landing-site distributions resemble truncated normal distributions (with the missing tails reflecting saccades that undershot or overshot their intended targets) that are centered on words and that become more variable with saccade length (McConkie, Kerr, Reddix, \& Zola, 1988; McConkie et al., 1991; O'Regan, 1981; O'Regan \& Lévy-Schoen, 1987). The model also accounts for the finding that refixations are more likely following initial fixations near the beginnings and ends of words, presumably because such refixations allow lexical processing to continue from better viewing locations (Rayner, Sereno, \& Raney, 1996; Vitu, McConkie, Kerr, \& O'Regan, 2001).

The model as described thus far was explicitly designed to explain only the situation that occurs when the reader is proceeding through the text without any problems, with ongoing lexical processing being the "engine" that "drives" the eyes forward. Consistent with this conceptualization, the model has only been used to simulate the data from eye-movement experiments in which sentences containing backward eye movements (i.e., regressions) have been excluded, under the assumption that the majority of these regressions reflect difficulty with higher level language processing. Thus, with only a few exceptions, the model has said almost nothing about how higher level language processing influences eye movements during read- 
ing. These exceptions have mostly involved cases where ad hoc assumptions were included to allow the model to simulate particular experimental results.

For example, an assumption about postlexical processing was added to E-Z Reader 7 (Reichle, Rayner, \& Pollatsek, 2003) to simulate the patterns of eye movements observed when Finnish speakers read Finnish sentences containing long compound words (Pollatsek, Reichle, \& Rayner, 2003). Across several experiments (Hyönä \& Pollatsek, 1998; Pollatsek, Hyönä, \& Bertram, 2000), the lengths and/or frequencies of both the compound words and their constituent morphemes were orthogonally manipulated. The results of these experiments indicated that properties of both the words and their constituents affected readers' eye movements, with earlier dependent measures (e.g., the durations of the first fixations on the words) reflecting properties of the first constituents, and later measures (e.g., gaze durations, or the sum of all fixation durations during first-pass reading) reflecting properties of both the second constituents and the compounds. To simulate these data, it was necessary to add a processing stage to the model in which the meanings of the individual constituents (which were processed serially, much like individual words in simulations of English) were combined to produce the overall meaning of the word. Because this process of combining the meanings of the two constituents was assumed to begin only after both of the constituents had been identified, this additional stage of meaning composition can be described as being postlexical.

Postlexical processing was also added to E-Z Reader 9 (Pollatsek et al., 2006c) to explain why older readers are more likely to first skip and then regress back to words than are college-age readers (Rayner, Reichle, Stroud, Williams, \& Pollatsek, 2006). Three assumptions were necessary to simulate this result. The first was that older readers are more likely to take advantage of their additional years of reading experience and use predictability to guess upcoming words, but sometimes these guesses are incorrect. The second was that incorrectly guessed words are identified as such during postlexical processing, presumably because the meanings of the misidentified words are impossible to integrate into the overall meaning of the sentence. The final assumption was that the misidentified words have to be reprocessed, resulting in interword regressions.

Finally, prior to our development of E-Z Reader 10, a preliminary version of this model (i.e., one containing a subset of the E-Z Reader 10 assumptions) was used to examine several possible explanations for why readers make longer fixations on nouns in adjective-noun sequences when the adjectives are short in length, as compared with when they are long (i.e., the reverse word-length effect; Pollatsek et al., 2008). This preliminary version included a stage of postlexical processing and an assumption that attention requires some amount of time to shift from one word to the next, but differed from E-Z Reader 10 in this article in several important ways (see Pollatsek et al., 2008). More important, the preliminary version was not evaluated with respect to either the benchmark phenom- ena (e.g., word frequency effects) that have been used to evaluate prior versions of E-Z Reader and other models of eye-movement control, or the phenomena (e.g., interword regressions) that motivated the new assumptions of our model.

The preceding examples indicate how, on three separate occasions, assumptions about postlexical processing were incorporated into E-Z Reader. In all three examples, this postlexical processing normally lagged behind lexical processing, but occasionally intervened to slow or halt lexical processing and the forward progression of the eyes, causing both attention and the eyes to be directed back to the location of integration difficulty. In the new version of the model described below, this basic mechanism is retained, but is more precisely specified.

\section{New Assumptions}

Figure 1B is a schematic diagram of E-Z Reader 10. As we will show, this model can be used to examine how the time course of higher level, postlexical language processing might influence readers' moment-to-moment decisions about when and where to move their eyes. This version of E-Z Reader differs from its predecessor in that it includes two new assumptions.

The first new assumption is that shifting attention from one word to another during reading requires some amount of time. This is indicated by the box labeled "A" in Figure 1B. This assumption was added in response to criticism of the model's previous assumption, that attention shifts from word $n$ to word $n+1$ were instantaneous (Inhoff, Eiter, \& Radach, 2005; Inhoff, Radach, \& Eiter, 2006; Radach, Deubel, \& Heller, 2003; Radach, Reilly, \& Inhoff, 2007; however, for a rebuttal of these criticisms, see Pollatsek, Reichle, \& Rayner, 2006a, 2006b). In E-Z Reader 10 , the mean time required to shift attention, $t(\mathrm{~A})$, is now a random deviate that is sampled from a gamma distribution with a mean equal to $\mathrm{A}=50 \mathrm{msec}(S D=$ $0.22 \mathrm{~A}$ ). The time required to shift attention from one word to the next is thus broadly consistent with several empirical estimates of how long it takes to move attention (for a review, see Egeth \& Yantis, 1997) and may be conservative, given evidence suggesting that attention shifts require only 4-33 msec per degree of visual angle ${ }^{2}$ (Eriksen \& Schultz, 1977; Jolicœur, Ullman, \& Mackay, 1983; Posner, 1978; Shulman, Remington, \& McLean, 1979; Tsal, 1983). The fact that previous versions of the model were used only to simulate the forward progression of eye movements meant that attention shifts were always progressive, ensuring that words were always identified in their correct order. However, in E-Z Reader 10, problems with postlexical integration can occasionally result in regressive attention shifts.

The second new assumption of E-Z Reader 10 is that a postlexical integration stage (labeled "I" in Figure 1B) begins on word $n$ immediately after its identification (i.e., after the completion of $\mathrm{L}_{2}$ on word $n$ ). This stage is assumed to reflect all of the postlexical processing necessary to integrate word $n$ into the higher level representations that readers construct online-for example, linking 
word $n$ into a syntactic structure, generating a contextappropriate semantic representation, and incorporating its meaning into a discourse model. Note that, as with our assumptions about both attention and lexical processing, our assumptions about postlexical language processing are intended to be only a high-level description of how this stage of processing interacts with lexical processing and attention, and thereby affects readers' eye movements. In other words, the integration stage shown in Figure 1B is a placeholder for a deeper theory of postlexical language processing during reading. Our goal in including this stage is therefore quite modest: to provide a tentative account of how-within the framework of the E-Z Reader model-postlexical variables might affect readers' eye movements. Finally, we make six specific assumptions about this postlexical stage: (1) The time required to complete $\mathrm{I}, t(\mathrm{I})$, is sampled from a gamma distribution having a mean of I $=25 \mathrm{msec}(S D=0.22 \mathrm{I})$; (2) the predictability information that is normally used to constrain the identity of word $n+1$ (see Equations 1 and 3 ) is available only after word $n$ has been integrated; (3) the failure to integrate word $n$ before the identification of word $n+1$ constitutes integration failure, resulting in comprehension difficulty; (4) with probability $p_{\mathrm{F}}$, the integration of word $n$ fails, also resulting in comprehension difficulty; (5) either type of integration failure will, with probability $p_{\mathrm{N}}$, cause both the eyes and attention to be directed back to the point at which the difficulty became evident (i.e., word $n$ ), as opposed to some earlier sentence location (with probability $1-p_{\mathrm{N}}$ ); and (6) regressive saccades require some additional amount of time to program, as compared with progressive saccades. The new assumptions about attention and postlexical integration thus add five new free parameters to the model $-\mathrm{A}, \mathrm{I}, p_{\mathrm{F}}, p_{\mathrm{N}}$, and the extra time that is necessary to program regressions. In what follows, we will provide justifications for these assumptions.

First, regarding the duration of I: Although $25 \mathrm{msec}$ may seem very short, our assumption is that the duration of I reflects the minimal amount of postlexical processing that (on average) is necessary to satisfy the languageprocessing system that comprehension is proceeding without difficulty and that it is not necessary to interrupt lexical processing and/or halt the progression of the eyes. This assumption does not preclude the possibility that additional postlexical processing occurs on many or even all words. Our conceptualization of postlexical processing is thus broadly consistent with the "good enough" view of language processing (Ferreira, Bailey, \& Ferraro, 2002; Ferreira \& Patson, 2007; Swets, Desmet, Clifton, \& Ferreira, 2008) and with work by Sanford and colleagues (Sanford, 2002; Sanford \& Garrod, 2005), in that we are assuming that complete incremental postlexical processing is not always required and may not always occur. Finally, although one could hypothesize that words that are difficult to identify should also be difficult to integratethat is, that $t(\mathrm{I})$ should be correlated with $t\left(\mathrm{~L}_{1}\right)$ and $t\left(\mathrm{~L}_{2}\right)$ we adopted the simplifying assumption of independence between lexical and postlexical processing to make the modeling less complicated, and because one of the phe- nomena simulated below (i.e., the pauses that occur at clause boundaries; Just \& Carpenter, 1980) does not involve difficulty with lexical processing per se.

Second, regarding the assumption that a word's predictability may help to constrain its identity only if the prior word has already been integrated: This assumption is based on the fact that a word's cloze predictability reflects all of the lexical and postlexical constraints that are predictive of that word's identity after all of the preceding words have been fully processed (Balota et al., 1985; Ehrlich \& Rayner, 1981; Rayner et al., 2004; Rayner \& Well, 1996). As such, cloze predictability reflects a variety of different constraints, including those that are imposed by both low-level (e.g., semantic priming) and high-level (e.g., syntactic constraints) processing. In the simulations reported below, we adopted the conservative assumption that the predictability of word $n$ is set equal to 0 when calculating the durations of $\mathrm{L}_{1}$ and/or $\mathrm{L}_{2}$ (see Equations 1 and 3), if the integration of word $n-1$ has not completed by the time lexical processing (i.e., $\mathrm{L}_{1}$ and/ or $\mathrm{L}_{2}$ ) of word $n$ begins. This assumption is conservative because it ignores the (probably weak) contributions of the lower level sources of predictability (e.g., semantic priming), and because it imposes a (nontrivial) constraint on the rate of lexical processing.

Third, regarding the assumption that failure to integrate word $n$ prior to the identification of word $n+1$ results in comprehension difficulty: The intuition behind this assumption is that, in some cases, integrative processing on word $n$ may not converge quickly or even at all, so that integration of word $n+1$ will not be possible. We hypothesize that, in such situations, the default process is to interrupt the forward movement of the eyes and attention and to make a regression back to the point at which processing difficulty was first encountered (per the fifth assumption; see below).

Fourth, regarding the probability $p_{\mathrm{F}}$, that integration "fails," resulting in comprehension difficulty, the intuition behind this assumption is that, for a variety of different reasons (e.g., perceptual errors; Pollatsek et al., 2008), the integration of a word can sometimes fail. Sometimes this failure occurs rapidly enough to result in an immediate pause and/or a regression (again, per the fifth assumption). In the simulations reported below, we will provide examples of how rapidly occurring problems with integration can result in patterns of eye movements that have, until now, been explained in only a very cursory, verbal manner.

Fifth, regarding our assumption that following comprehension failure, the eyes and attention will, with probability $p_{\mathrm{N}}$, be directed back to word $n$, the location where comprehension difficulty was first encountered: This is a simplifying assumption based on findings that the average length of readers' initial regressive eye movements are often quite short, moving the eyes back only a word or two (Rayner \& Pollatsek, 1989; Vitu \& McConkie, 2000), although this length may be correlated with how much sentential material appears before the integration breakdown (Apel, Henderson, \& Ferreira, 2007). There is also some evidence that readers are capable of accurately di- 
recting their gaze back to sources of processing difficulty, rather than, for example, simply rereading the entire sentence (Frazier \& Rayner, 1982; Kennedy, Brooks, Flynn, \& Prophet, 2003; Kennedy \& Murray, 1987; however, cf. Weger \& Inhoff, 2007). However, to fully implement directed long-distance regressions like this in our model would require a more detailed account of language processing and reanalysis. It would also require an account of how the spatial coordinates of the words are represented in memory. To make our modeling possible in the absence of such accounts, we adopted the simplifying assumption that whatever comprehension problem occurred during the integration of word $n$ will, with probability $p_{\mathrm{N}}$, cause the eyes and attention to be directed back to word $n$, and with probability $1-p_{\mathrm{N}}$, cause the eyes and attention to be directed back to some earlier location in the sentence. For the sake of convenience, this earlier location was always defined to be word $n-1$. Our assumption is that by moving the eyes and attention back to the "problematic" word (whether it be $n$ or $n-1$ ), that word can be reprocessed (i.e., $\mathrm{L}_{1}, \mathrm{~L}_{2}$, and I are completed a second time on the word), allowing the language system to attempt to fix the problem. We make no attempt to explain how the language system does this; but to avoid potential problems associated with infinite loops (e.g., due to integration's always failing on a particular word), we assumed that the probability of integration failure was very small during the second pass through the sentence.

Finally, we assumed that regressive saccades take an additional $30 \mathrm{msec}$ to program (i.e., $\mathrm{M}_{1}$ for regressions is increased by $30 \mathrm{msec}$ ), consistent with results showing that regressions to previously fixated viewing locations require an additional $20-36 \mathrm{msec}$ to initiate or program (Rayner, Juhasz, Ashby, \& Clifton, 2003). This 30-msec constant is added to all regressive saccades in all of the simulations reported below.

The main consequences of the preceding assumptions are schematically illustrated in Figure 2. The situation depicted in Figure 2A is the most frequently occurring one: Comprehension is proceeding without difficulty, and the eyes are continuing to move forward along the line of text. We will refer to this as the "default" reading process. In Figure 2A, the first stage of lexical processing $\left(\mathrm{L}_{1}\right)$ of word $n$ completes, causing the oculomotor system

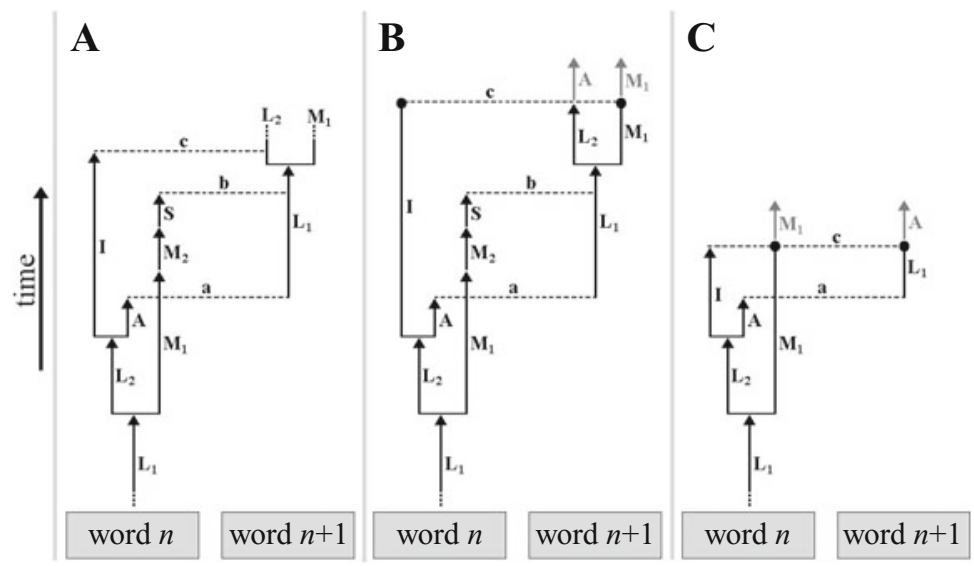

Figure 2. Schematic diagram showing three possible sequences of events that can occur in E-Z Reader 10. In all three panels, arrows indicate completed processes and solid circles indicate terminated processes. Panel A depicts the most common situation-when integration occurs without difficulty. The completion of the first stage of lexical processing $\left(\mathrm{L}_{1}\right)$ of word $n$ results in the continuation of the second stage $\left(L_{2}\right)$ and the initiation of a saccadic program $\left(M_{1}\right)$ to move the eyes to word $n+1$. The completion of $L_{2}$ causes attention (A) to shift to word $n+1$ and initiates postlexical integration (I) of word $n$. As soon as attention finishes shifting to word $n+1$ (represented by the dotted line labeled "a"), lexical processing $\left(\mathrm{L}_{1}\right)$ of that word begins. The nonlabile stage of saccadic programming $\left(M_{2}\right)$ then completes and the saccade is executed $(S)$, moving the eyes to word $n+1$ (represented by the dotted line "b"). (Parafoveal processing of word $n+1$ thus occurs in the time interval between "a" and "b.") Finally, the meaning of word $n$ is integrated (indicated by "c") before lexical processing $\left(L_{2}\right)$ of word $n+1$ finishes, and the eyes continue to move forward. Panel B shows the situation where the integration (I) of word $\boldsymbol{n}$ fails to complete before the lexical processing $\left(\mathrm{L}_{2}\right)$ of word $n+1$ completes. With this "stalling out" of integration, the labile saccadic program to move the eyes to word $n+2$ is canceled, and both the eyes and attention are drawn back to the location where comprehension difficulty first became apparent (represented by the gray arrows labeled "A" and " $M_{1}$ "). Finally, panel $C$ shows what can happen when the early detection of a violation during the integration (I) of word $\boldsymbol{n}$ results in the termination of integrative processing, interrupting lexical processing $\left(A, L_{1}\right.$, or $\left.L_{2}\right)$ of word $n+1$ and causing both the eyes and attention to move back. 
to begin programming a saccade $\left(\mathrm{M}_{1}\right)$ to move the eyes to word $n+1$. While this is happening, the second stage of lexical processing $\left(\mathrm{L}_{2}\right)$ finishes, initiating the postlexical integration (I) of that word and an attention shift (A) to the next. After some amount of time, attention finishes shifting to word $n+1$ (indicated by the dotted line labeled "a"), and lexical processing $\left(\mathrm{L}_{1}\right)$ of that word begins. Because word $n$ is still being integrated, however, the lexical processing of word $n+1$ does not benefit from whatever information is known about that word's predictability. Integration of word $n$ and lexical processing of word $n+1$ continue, while the second stage of saccadic programming $\left(\mathrm{M}_{2}\right)$ completes, and a saccade (S) is executed to move the eyes to word $n+1$ (the dotted line labeled "b"). Parafoveal processing of word $n+1$ thus occurs from word $n$ in the time interval between "a" and "b." Finally, integration of word $n$ completes (dotted line labeled "c"), while both lexical processing and the eyes continue their forward progression. It is important to note that although the lexical processing of word $n+1$ did not benefit from the use of predictability information, the relative time course of integration versus lexical processing is often such that predictable words are processed more rapidly (and sometimes even skipped) more than are less predictable words.

Figure 2B illustrates one situation that can disrupt the default reading process - in this case, word $n$ is so difficult to integrate that its integration lags far behind ongoing lexical processing, causing problems with the postlexical processing of word $n+1$. In the situation depicted in the figure, word $n+1$ is identified (i.e., $\mathrm{L}_{2}$ completes) before word $n$ has been integrated, which, by our third assumption, halts both the postlexical processing (I) of word $n$ and the forward movement of the eyes (e.g., in this example, $\mathrm{M}_{1}$ is canceled), so that both attention and the eyes can be directed back to the source of processing difficulty (as indicated by the gray arrows labeled " $\mathrm{A}$ " and " $\mathrm{M}_{1}$," respectively). The intuition behind this assumption is that the severity of comprehension problems arising from the slow postlexical processing of a word can be minimized by allowing such slowdowns to "put the brakes on" the default reading process.

Finally, Figure $2 \mathrm{C}$ illustrates a second situation that can disrupt the default reading process - rapid integration failure. In this situation, the early detection of a violation results in the termination of integrative processing (e.g., as might occur if one attempts to integrate a word into an incompatible syntactic structure; Frazier \& Rayner, 1982). In the example, integration on word $n$ terminates before the labile saccadic program $\left(\mathrm{M}_{1}\right)$ to move the eyes from word $n$ to word $n+1$ has completed. This causes lexical processing $\left(\mathrm{L}_{1}\right)$ of word $n+1$ to stop and attention (A) to be directed back from word $n+1$. But instead of the eyes moving back from word $n+1$, the labile program that would have moved the eyes forward is canceled, increasing the duration of the (first) fixation on word $n$, and sometimes resulting in an intraword or interword regression (because of saccadic error) back to word $n-1$.

Of course, we acknowledge that our assumptions regarding interword regressions are limited, because they explain only the relatively short regressions that move the eyes back a word or two. Although this is sufficient to explain regressions that result from relatively local integration problems that are rapidly noticed by the reader, our assumptions are not sufficient to explain regressions that result from earlier processing difficulty or problems that are noticed only after some delay. As a result, the model cannot explain long-distance regressions. However, in order for the model to capture such long-distance regressions, it would require a full articulation of language processing, instead of our simple assumptions about how postlexical processing interacts with lexical processing, and it would also need an account of how a reader's spatial representation of the text allows him or her to regress back to locations indicated by the model of language processing. Such an account is beyond the scope of our model.

\section{Simulation Results}

The simulations reported below were completed using the sentences from the Schilling et al. (1998) corpus as "frames" to examine how the variables associated with the target words in each of the experimental conditions would affect the simulated patterns of eye movements on those target words. ${ }^{3}$ The corpus consists of 48 independent sentences, each containing 8-14 words. Although such sentences are probably not representative of the types of sentences that readers normally encounter in naturally occurring connected discourse, simulations using French passages (Miellet, Sparrow, \& Sereno, 2007) and Chinese sentences (Rayner, Li, \& Pollatsek, 2007) have indicated that the basic principles of the E-Z Reader model seem to be robust enough to generalize beyond the type of simple English sentences of our corpus. In addition, in all of the simulations of the experiments reported below, the critical (target) words from actual sentences that were used in the experiments were inserted into the Schilling et al. sentence frames as proxies for the full sentences. For example, in our simulation of the Warren and McConnell (2007) experiment examining plausibility and violations of selectional restrictions, the actual target words that were used in that experiment (word $n$ ) and the words immediately before (word $n-1$ ) and after (word $n+1$ ) the targets were embedded in the Schilling et al. sentences. These critical words were embedded into random locations (but were never the first or last word) in order to avoid potential biases in what the model was doing immediately before and after encountering the critical words. We will say more about how this was done as the various simulations are described.

Each simulation was completed using 1,000 Monte Carlo runs of the model per condition; the predicted measures that are reported (e.g., gaze durations) were computed exactly as in the simulated experiments. With the exceptions that are discussed next, the values of the free parameters were (unless otherwise indicated) set equal to the values that were used in previously published simulations and that were based on estimates of the time required to identify words, to program saccades, and so on (for an overview of these parameters and their values, see Pollatsek et al., 2006c, or Reichle et al., 2006). 
The changes were as follows: First, the values of the four parameters that control the rate of lexical processing were adjusted to decrease the time required to identify words, and thereby to offset the additional time required for shifting attention between words. The values of $\alpha_{1}, \alpha_{2}$, $\alpha_{3}$, and $\Delta$ (see Equations 1 and 3 ) were thus respectively changed from 122, 4, 10, and 0.5 (the values used in E-Z Reader 9) to 98, 2, 27, and 0.25 (the values used in E-Z Reader 10). The mean time to complete the labile stage of saccadic programming, $M_{1}$, was increased from $100 \mathrm{msec}$ (E-Z Reader 9) to $125 \mathrm{msec}$ (E-Z Reader 10) to compensate for this speedup in lexical processing; increasing the value of this parameter slowed saccadic programming, which in turn increased the mean durations of the fixations. The absolute sizes of these adjustments were fairly modest and are still consistent with empirical estimates of word identification and saccadic programming latencies. For example, the mean time to identify the most frequent word, the, when it is directly fixated and its predictability is 0 is $183 \mathrm{msec}$ in E-Z Reader 9 and $159 \mathrm{msec}$ in E-Z Reader 10. Similarly, the smaller value of the $\Delta$ parameter ensures that the mean predicted preview effect (across the full range of word frequencies, with predictability equal to 0 and ignoring the effect of visual acuity) is comparable for the two versions of the model: $75 \mathrm{msec}$ for E-Z Reader 9 and 78 msec for E-Z Reader 10.

Finally, the value of $R$, the parameter that determines the delay between when a word is first fixated and when the decision about whether to refixate the word is made, was reduced from $117 \mathrm{msec}$ (E-Z Reader 9) to $0 \mathrm{msec}$ (E-Z Reader 10). This change was motivated by the assumption that the feedback required to determine that the eyes had landed in a poor viewing location (i.e., one that affords a poor view of the word) is not based on visual information (as was previously assumed in E-Z Reader 9), but is instead based on efference copies of the saccade programs (Carpenter, 2000). This new assumption regarding corrective refixations is consistent with what is assumed in other models of eye-movement control during reading (e.g., Engbert et al., 2005). To keep the proportion of refixations comparable in E-Z Reader 10, the value of the parameter that modulates the tendency to refix (see Equation 7) was also reduced from $\lambda=0.09$ to $\lambda=0.05$.

The first three simulations were completed in order to investigate how the new assumptions of E-Z Reader 10 would affect the model's overall performance. To do this, we first examined the model's performance on the Schilling et al. (1998) sentence corpus and compared this performance with that of E-Z Reader 9 (Pollatsek et al., 2006c). The results of this first simulation are shown in Table 1, which displays the word-based means for six dependent measures for five classes of words (based on their frequency of occurrence) in the Schilling et al. corpus. These means were calculated excluding trials that contained interword regressions. Consequently, in the simulation using E-Z Reader 10, only the inclusion of the two new processes $(50 \mathrm{msec}$ for attention shifts and $25 \mathrm{msec}$ for postlexical integration) were evaluated; integration failure was not allowed $\left(p_{\mathrm{F}}=0\right)$. The observed data reflected only those sentences that were read by the participants without difficulty (i.e., trials that did not contain interword regressions). Any simulation trials that contained interword regressions due to slow integration or oculomotor error were excluded from our analyses.

As Table 1 shows, our new assumptions do not adversely affect the model's ability to fit the Schilling et al. (1998) corpus. This can be seen by comparing the means predicted by E-Z Reader 10 with its assumptions about attention and postlexical processing with both the observed means and those predicted by E-Z Reader 9. More formally, the model's goodness of fit can be quantified using the root-mean-square deviation (RMSD) between the observed and predicted means (see note 3 ), with smaller RMSDs indicating better overall fits. Using this measure, E-Z Reader 10 's fit is actually slightly better than that of its predecessor: 0.107 versus 0.153 , respectively. ${ }^{4}$ This result indicates that our new assumptions do not adversely affect the model's capacity to simulate the empirical results that it was originally designed to simulate.

The second exploratory simulation investigated how the probability of rapid integration failure, $p_{\mathrm{F}}$, affected the model's overall performance and the overall rate of making interword regressions. The results of this second simulation are shown in Figure 3. In this simulation, the probability of integration failure, $p_{\mathrm{F}}$, was incrementally increased from 0 to 1 (in 0.1 increments) for all of the words in all of the sentences, in order to determine how integration failure would influence the model's overall performance. As in the previous simulation, the values of $A$ and $I$ were set equal to 50 and $25 \mathrm{msec}$, respectively.

Table 1

Mean Observed (Schilling, Rayner, \& Chumbley, 1998) and Simulated (E-Z Reader 9 vs. E-Z Reader 10) Fixation Durations (in Milliseconds) and Probabilities, As a Function of Word Frequency

\begin{tabular}{|c|c|c|c|c|c|c|c|c|c|c|c|c|c|c|c|c|c|c|}
\hline \multirow{2}{*}{$\begin{array}{c}\text { Word Frequency } \\
\text { (Occurrences/Million) }\end{array}$} & \multicolumn{3}{|c|}{$\begin{array}{l}\text { First-Fixation } \\
\text { Duration }\end{array}$} & \multicolumn{3}{|c|}{$\begin{array}{l}\text { Single-Fixation } \\
\text { Duration }\end{array}$} & \multicolumn{3}{|c|}{ Gaze Duration } & \multicolumn{3}{|c|}{$\begin{array}{l}\text { Probability } 1 \\
\text { Fixation }\end{array}$} & \multicolumn{3}{|c|}{$\begin{array}{l}\text { Probability } 2+ \\
\text { Fixations }\end{array}$} & \multicolumn{3}{|c|}{ Probability Skip } \\
\hline & Obs. & 9 & 10 & Obs. & 9 & 10 & Obs. & 9 & 10 & Obs. & 9 & 10 & Obs. & 9 & 10 & Obs. & 9 & 10 \\
\hline $1-10$ & 248 & 251 & 246 & 265 & 259 & 256 & 29 & 295 & 293 & .6 & .75 & & .21 & .15 & & .10 & .09 & .15 \\
\hline & & & & & & & & & & & & & & & & & & \\
\hline & & 22 & 23 & & 22 & & & 24 & 24 & & & & & & 0 & .2 & 1 & \\
\hline 1,0 & 223 & 217 & 22 & 23 & 217 & 225 & 234 & 220 & 228 & .4 & .52 & .50 & .0 & .01 & .01 & .55 & .47 & \\
\hline $10,001+$ & 208 & 214 & 214 & 216 & 215 & 214 & 214 & 216 & 217 & .32 & .42 & .38 & .01 & .00 & .01 & .67 & .58 & .61 \\
\hline
\end{tabular}

Note-Goodness of fit, as measured by the RMSDs (smaller values indicate better fits), between the observed and simulated means are E-Z Reader 9, $\mathrm{RMSD}=0.153 ; \mathrm{E}-\mathrm{Z}$ Reader $10, \mathrm{RMSD}=0.107$ 


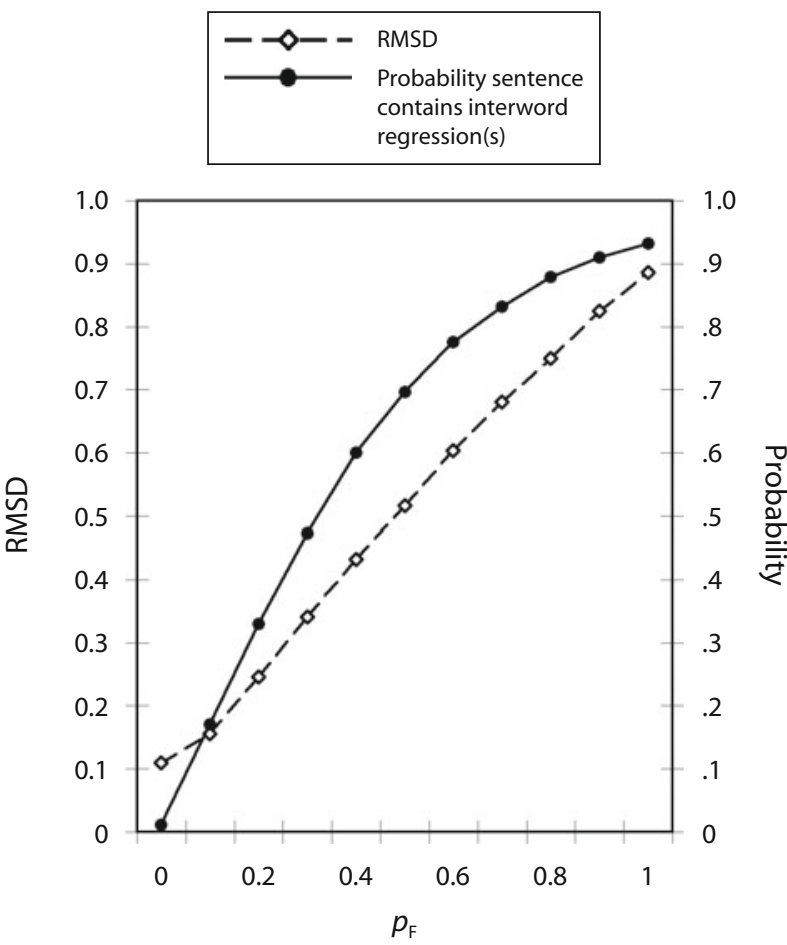

Figure 3. Simulation showing how the probability of integration failure $\left(p_{\mathrm{F}}\right)$ affects the model's overall goodness of fit (as measured using RMSDs) to the Schilling, Rayner, and Chumbley (1998) corpus, and the mean probability of one or more interword regressions occurring in the sentences. In the simulation, $t(I)=$ $25 \mathrm{msec}$, and $p_{\mathrm{N}}=1$.

The model's performance was again evaluated using its fit to the Schilling et al. (1998) corpus, as measured using RMSDs. Because one of the main reasons for running this simulation is to determine how the inclusion of interword regressions would affect the model's performance, the RMSDs were calculated using all simulation trials. In other words, sentences containing interword regressions were not excluded from our analyses, as they had been in the previous simulation. For the sake of simplicity, all regressions were directed back to the word that was the source of integration difficulty $\left(p_{\mathrm{N}}=1\right)$. Finally, we also calculated the mean probability that a given sentence contained one or more interword regressions, which, along with the RMSDs, are plotted as a function of $p_{\mathrm{F}}$ values in Figure 3.

As Figure 3 indicates, for $p_{\mathrm{F}}$ values of 0.4 or less, the model's overall capacity to explain the various fixation measures remains fairly robust, with RMSDs increasing only slightly, from 0.107 to 0.432 (see note 4 ). This suggests that the inclusion of a 25 -msec integration stage that fails for some nontrivial percentage of the words (up to $40 \%$ ) has only a modest effect on the model's overall ability to describe what happens during reading when comprehension is proceeding without too much difficulty and the dominant pattern of eye movements is normal (moving forward), but with occasional regressions. This conclusion is supported by the model's predictions regarding regressions. As Figure 3 indicates, the probability of a sentence containing one or more interword regressions is rather modest $(p \leq .6)$ for $p_{\mathrm{F}}$ values of 0.4 or less. This is interesting because, as previously mentioned, the E-Z Reader model was designed to explain only what we have called the "default" reading process; in fitting the model to the Schilling et al. (1998) sentence corpus, all trials that included interword regressions were excluded from consideration. As a result, only $36 \%$ of the original data were actually included in the corpus, which suggests that if the assumptions of the model are correct, integration failure occurred on approximately $40 \%$ of the words. Of course, this conclusion remains tentative, because it ignores the possibility that some interword regressions may have stemmed from other problems. For example, some portion of the regressions may reflect problems associated with incomplete lexical processing, as is posited by the SWIFT model of eye-movement control (Engbert et al., 2005). More will be said about these different possible sources of interword regressions in the Discussion.

Finally, the third exploratory simulation investigated how the parametric manipulation of the duration of the integration stage, $t(\mathrm{I})$, and the probability of rapid integration failure, $p_{\mathrm{F}}$, would affect the patterns of eye movements on specific target words. To do this, we set the properties of the Schilling et al. (1998) target words (word $n$ ) and the preceding (word $n-1$ ) and following (word $n+1$ ) words equal to fixed values (frequencies $=10$ per million, lengths $=6$ letters, predictabilities $=0.05$ ). The properties of these word triplets were controlled in this manner in order to determine how the parametric manipulation of $t(\mathrm{I})$ and $p_{\mathrm{F}}$ would affect the resulting patterns of simulated eye movements in a context devoid of any variability, due to the properties of the words themselves. The values of $t(\mathrm{I})$ and $p_{\mathrm{F}}$ were incrementally and orthogonally varied for word $n$, and the value of $p_{\mathrm{N}}$ was set equal to 1 . Four dependent measures were then calculated on word $n$ : the mean first-fixation and gaze durations, the total viewing times, and the probabilities of making interword regressions back to word $n$. The results of this simulation are shown in Figure 4.

Figure 4A shows the predicted first-fixation durations, and Figure 4B shows the predicted gaze durations. Both measures increase monotonically with values of $p_{\mathrm{F}}$, but first increase and then decrease with values of $t(\mathrm{I})$. The former pattern reflects the situation that was described in Figure 2C: As $p_{\mathrm{F}}$ increases, so does the probability that the resulting integration failure will cancel whatever labile saccade would have otherwise moved the eyes forward, resulting in a pause (increasing both the first-fixation and gaze durations) and/or a refixation (increasing the gaze duration). From a theoretical perspective, this result is interesting, because it suggests that problems with postlexical integration can sometimes have very rapid effects, influencing the first-fixation duration on the word being integrated, but that this situation happens only when the integration failure occurs before the labile program to move the eyes forward has completed.

The nonmonotonic relationship that is observed in Figures $4 \mathrm{~A}$ and $4 \mathrm{~B}$ between $t(\mathrm{I})$ and both the first-fixation and gaze durations reflects the fact that after a certain amount 
A

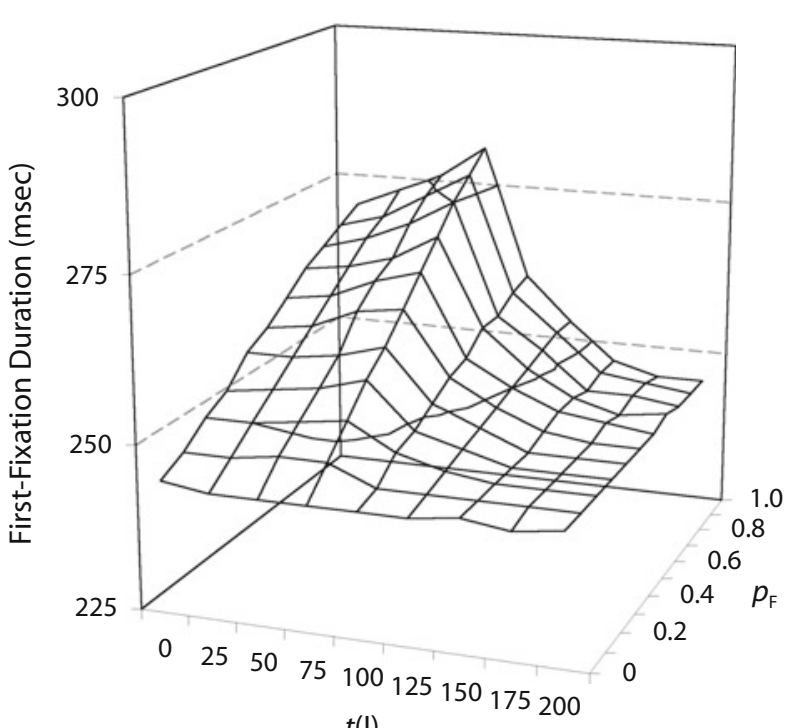

$t(\mathrm{I})$

C

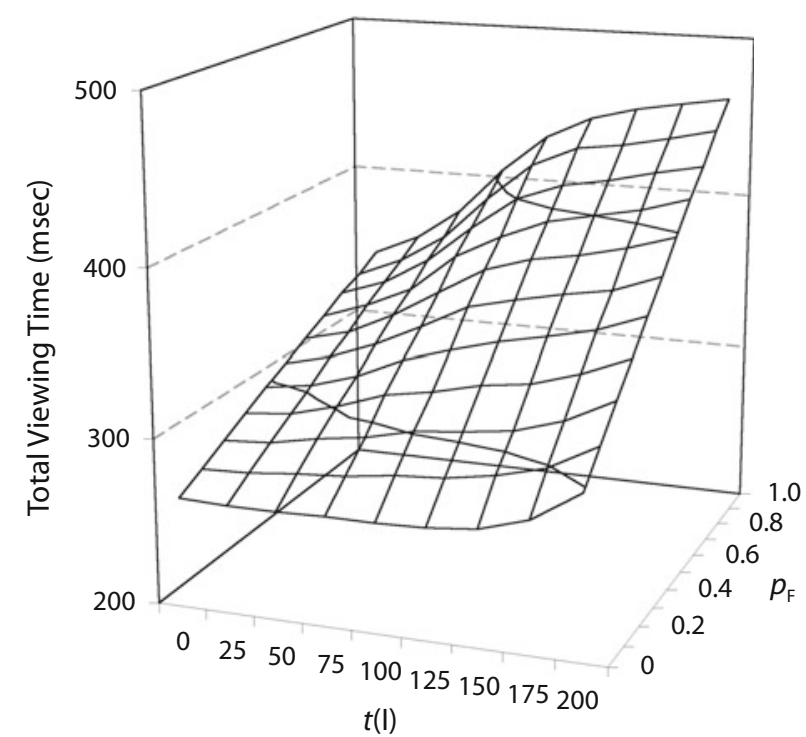

B

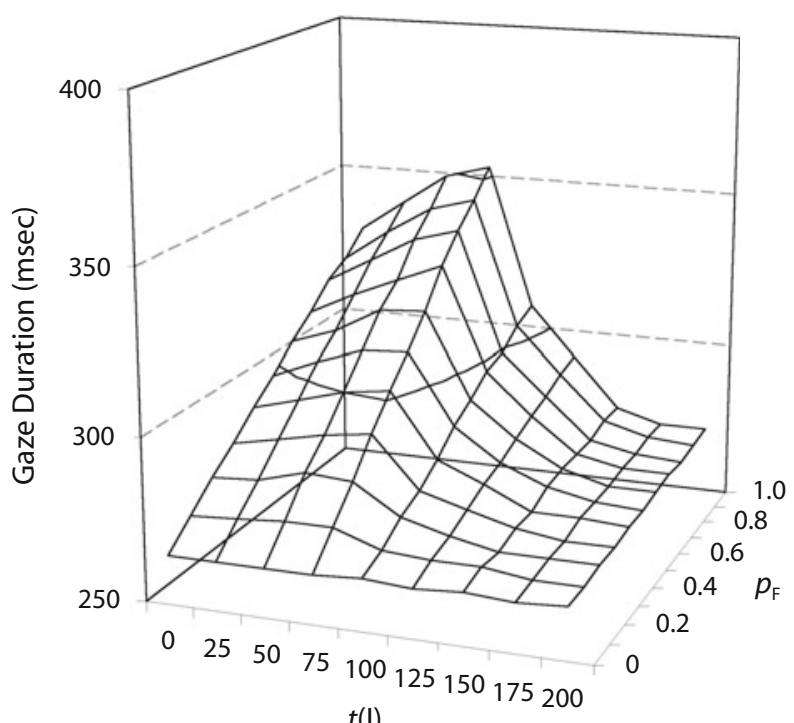

$t(\mathrm{I})$

D Probability of Making Regression Into Word n

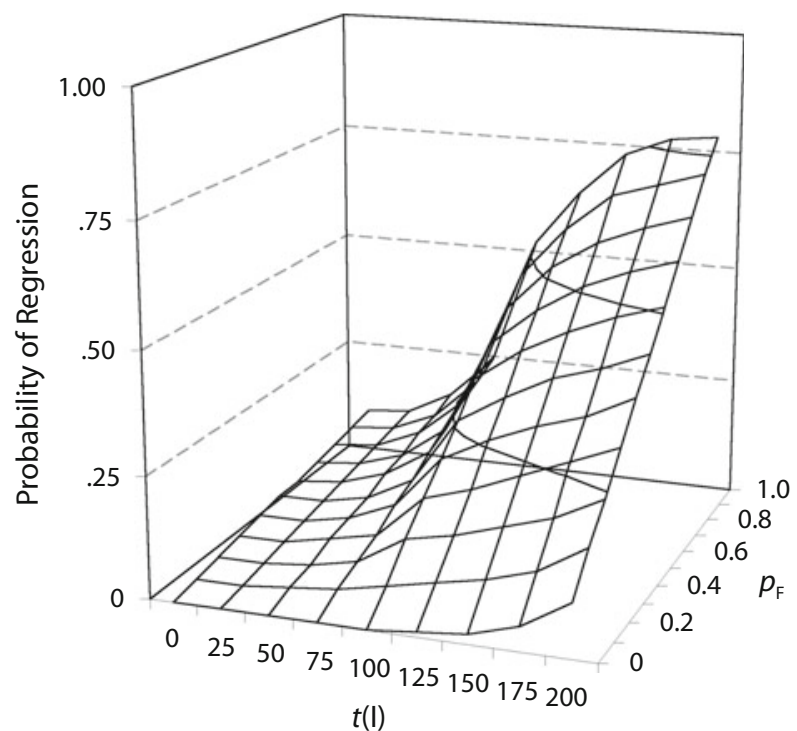

Figure 4. Simulation showing how the time required to complete integration, $t(I)$, and the probability that integration quickly fails, $p_{F}$, on word $n$ affect four dependent measures on that word: (A) First-fixation durations, (B) gaze durations, (C) total viewing times on word $n$, and (D) the probability of making a regression back to word $n$. In the simulation, $p_{\mathrm{N}}=1$. See the text for an explanation of the results.

of time has elapsed, the likelihood of completing the labile stage of saccadic programming increases dramatically, making the execution of that saccade obligatory, and thereby increasing the proportion of trials in which the eyes move from word $n$ to word $n+1$ before regressing back to word $n$ (similar to the situation described in Figure 2B). Thus, as $t(\mathrm{I})$ increases, so does the proportion of trials in which the eyes move off word $n$, causing both the mean first-fixation and gaze durations on that word to decrease.

Figure $4 \mathrm{C}$ indicates that the total viewing times on word $n$ increase with both $t(\mathrm{I})$ and $p_{\mathrm{F}}$. The first relationship is due to the fact that as $t(\mathrm{I})$ increases, so does the probability that word $n+1$ will be identified before word $n$ has been integrated, resulting in a regression back to word $n$ and increasing the total viewing times on that word (see Figure $2 \mathrm{~B}$ ). Similarly, as $p_{\mathrm{F}}$ increases, the first-fixation and gaze durations on word $n$ increase for the reasons discussed above, and in cases involving large values of $t(\mathrm{I})$, an increasing $p_{\mathrm{F}}$ increases the probability of making regressions back from word $n+1$. The latter explanation involving regressions is supported by Figure 4D, which shows the mean probability of making a regression into 
word $n$ as a function of $t(\mathrm{I})$ and $p_{\mathrm{F}}$; as was true of the total viewing times, this dependent measure also increases monotonically with both parameters.

What are the implications of the preceding simulations? The first is that the addition of some nonzero amount of time (on average, $50 \mathrm{msec}$ ) to move attention from one word to another does not disrupt the model's overall performance. The addition of this assumption allows us to counter criticism (Inhoff et al., 2006; Radach et al., 2003; Radach et al., 2007) that has been made against earlier versions of E-Z Reader - that the model is not plausible, because it assumes that the process of shifting attention from one word to the next is instantaneous (Egeth \& Yantis, 1997). As postulated elsewhere (Pollatsek et al., 2006a, 2000b; Rayner, Pollatsek, \& Reichle, 2003), these criticisms can be addressed by simply positing that some small portion of the time that is normally required for identifying a given word - such as some small portion of $t\left(\mathrm{~L}_{2}\right)$-also subsumes the time that is required for shifting attention to or from that word. The present simulations indicate that this solution is feasible, thus providing proof against claims that the addition of an explicit attentionshifting time would be fatal to the model's performance.

These simulations also demonstrate that a postlexical stage of language processing can run invisibly in the background of ongoing lexical processing — even though this higher level stage of processing requires a nonzero amount of time (in our simulations, an average of $25 \mathrm{msec}$ per word) to complete, and even though one aspect of lexical processing (the use of word predictability information) is contingent on its completion. The next set of simulations provides a more explicit test of the consequences of lengthening the duration of the postlexical integration stage and the probability of its failing in order to determine whether this manipulation can account for the patterns of pauses and/or regressions that have been observed when readers encounter problems with postlexical processing. In the first of these simulations, we examined the model's capacity to explain clause wrap-up effects.

A clause wrap-up effect is an example of a relatively robust effect that has, in the eye-movement literature, generally been attributed to higher level linguistic processing (Just \& Carpenter, 1980; Rayner, Sereno, Morris, Schmauder, \& Clifton, 1989). This effect refers to the finding that readers tend to fixate longer on, and make longer saccades from, a word when it ends a punctuationmarked clause or sentence than when it does not (Hill \& Murray, 2000; Hirotani, Frazier, \& Rayner, 2006; Rayner, Kambe, \& Duffy, 2000). The following results summarize what has been reported in eye-movement experiments that have examined clause wrap-up: (1) Gaze durations are longer on words ending sentences than on comma-marked clauses (Hirotani et al., 2006) and longer on words ending comma-marked clauses than on clause-internal words (Hirotani et al., 2006; Rayner et al., 2000); (2) these longer gaze durations are due to more intraword regressions (Rayner et al., 2000); (3) readers are less likely to regress across a punctuation-marked boundary than across no boundary or an unmarked boundary (Hirotani et al., 2006); and (4) saccades into new clauses or sentences are longer than within-clause saccades (Hirotani et al., 2006; Rayner et al., 2000). These effects have classically been thought to reflect the end-of-clause processing that is associated with completing any unfinished, within-clause interpretation and with performing intraclause or sentence integration (Just \& Carpenter, 1980).

If clause wrap-up effects are related to readers' completion of unfinished, postlexical processing at the end of a clause, they are suitable for modeling with E-Z Reader 10. This is because if the final word of a clause or sentence is more prone to integration failure, this will increase the probability of either refixating that word or regressing back to the previous word. The model might therefore predict refixations on, and/or regressions back from, clause-final words. To test this hypothesis and to examine the model's capacity for accounting for clause wrap-up effects, we completed a simulation that was loosely based on the Rayner et al. (2000) experiment that was described above.

To complete these simulations, we again used the Schilling et al. (1998) sentence frames (see note 3 ) in order to examine the consequences of the manipulations of interest on the simulated eye movements. In the simulations, we examined the consequence of having nouns in either clause-final positions (e.g., “. . . owned the instrument, already ...") or non-clause-final positions (e.g., ". . . owned the instrument already, . ..") within sentences. Table 2 shows the observed values of four dependent measures that were observed in these two conditions - the first-fixation and gaze durations on the nouns, as well as the probabili-

Table 2

Observed (Rayner, Kambe, \& Duffy, 2000) and Simulated

(E-Z Reader 10) Wrap-Up Effects on Clause-Final (CF)

and Non-Clause-Final (NCF) Nouns, in Milliseconds

\begin{tabular}{lcccccccc}
\hline & \multicolumn{4}{c}{ Observed } & & \multicolumn{3}{c}{ Simulated } \\
\cline { 2 - 4 } \cline { 6 - 8 } \multicolumn{1}{c}{ Dependent Measure } & CF & NCF & Difference & & CF & NCF & Difference \\
\hline First-fixation duration & 272 & 271 & 1 & & 263 & 260 & 3 \\
Gaze duration & 316 & 294 & 22 & & 308 & 287 & 21 \\
Probability of refixation & .14 & .09 & .05 & & .16 & .10 & .06 \\
Probability of regression & .07 & .13 & -.06 & & .08 & .13 & -.05 \\
\hline
\end{tabular}

Note-For non-clause-final words, $t(\mathrm{I})=25 \mathrm{msec} ; p_{\mathrm{F}}=0 ; p_{\mathrm{N}}=0.59$. For clause-final words, $t(\mathrm{I})=86 \mathrm{msec} ; p_{\mathrm{F}}=0.12$ (i.e., for nouns in the $\mathrm{CF}$ condition; e.g., instrument) versus 0.23 (i.e., for postnouns in the NCF condition; e.g., already); $p_{\mathrm{N}}=0$. 
ties of refixating the nouns and the probabilities of making regressions back into the nouns from the postnoun region. The latter measure is included, because it indicates the relative likelihood of making regressions across clause boundaries in the two conditions. All of these measures are collapsed across conditions of the Rayner et al. (2000) experiment involving low-typical versus high-typical nouns, because this manipulation was irrelevant to the issues being explored - the nature of clause wrap-up effects. The important points to note about the observed data are that first-fixation durations are not affected by clause wrap-up, but gaze durations are, and the probability of making a regression across the clause boundary (i.e., the location marked by a comma) is less than the probability of making a regression in the same location when it is not a clause boundary. Our hypothesis was that these effects could be accounted for by manipulating the characteristics of postlexical integration in the model.

Table 2 also shows the values that the model generated for these same dependent measures. These results were obtained by first embedding the critical nouns (word $n$ ) and the words immediately before (word $n-1$ ) and after (word $n+1$ ) them into 32 of the Schilling et al. (1998) sentences. This was done to ensure that the properties of these words were as closely matched as possible across the experiment and simulation. Because the cloze predictabilities of these words were not known, the predictabilities of words $n$ and $n+1$ were set equal to 0 ; however, because word $n-1$ was the in 29 of the 32 Rayner et al. (2000) sentences, its predictability was set equal to 0.9 . (The qualitative pattern of the simulation results is not dependent on these assumptions about predictability.) The length of word $n+1$ was also set equal to nine letters to better equate these words to the postnouns regions (which actually consisted of one to three words) that were used by Rayner et al. (2000). Finally, the lengths of the clausefinal words were also increased by one character to represent the presence of the clause-marking comma.

The simulation used the same parameter values used in previous simulations. Although one could argue that this is overly conservative (because the Rayner et al., 2000, experiment used participants and materials different from those that were used to select the model's parameter values), we would counter that this conservative approach provides a stronger test of the model's core assumptions. To test our hypothesis about clause wrap-up being related to $t(\mathrm{I})$, we attempted to simulate the observed pattern of results by setting the duration of $t(\mathrm{I})$ equal to $86 \mathrm{msec}$ for the clause-final words and $25 \mathrm{msec}$ (i.e., the parameter's default value) for all of the other words. The probability that this postlexical processing would result in some type of integration failure, $p_{\mathrm{F}}$, was set equal to 0.12 for the clause-final nouns, 0.23 for the postnoun clause-final words, and 0 for all of the other words in the sentences. The probability that such failures would cause the eyes and attention to move back to the point where integration difficulty was initially detected, $p_{\mathrm{N}}$, was set equal to 0 for clause-final words and 0.59 for all other words. This assumption - that $p_{\mathrm{N}}=0$ for clause-final words-meant that more of the regressions resulting from integration dif- ficulty were directed from the clause-final words to the immediately preceding words. These parameter values minimized the RMSDs between the observed and simulated refixation and regression probabilities in the two conditions.

As Table 2 shows, the model does a fairly good job of capturing the absolute values of the four reported dependent measures, as well as the effects of the experimental manipulation (e.g., as indicated by the columns showing the difference scores). Note that the model correctly simulates the finding that gaze durations are longer in the clause-final than in the non-clause-final conditions (observed difference, $M=22 \mathrm{msec}$; simulated difference, $M=21 \mathrm{msec}$ ). Moreover, the model accurately captures the fact that this difference largely reflects the higher probability of making a refixation in the clausefinal condition, and that it is not due to an increase in the first-fixation durations. Finally, the model accurately predicts the correct pattern of regressions, with fewer regressions being directed back from words that follow clause boundaries than from words that do not. These simulation results suggest that the additional time required to complete the postlexical processing of a clause-final word, in conjunction with our assumptions that this processing is more prone to failure and more likely to result in interword regressions back from the sources of integration difficulty, provides a viable explanation of the types of clause wrap-up effects that were reported by Rayner et al. (2000) and others (Hill \& Murray, 2000; Hirotani et al., 2006; Rayner et al., 1989). Our manipulation of the $p_{\mathrm{F}}$ parameter is loosely consistent with the notion that readers may set a higher threshold for coherence or integration at clause boundaries than at clause-internal positions, making integration failure more likely to occur.

Up to this point, our simulations have focused on how difficulty with postlexical integration interrupts the forward movement of the eyes, resulting in regressions back from the location of the integration difficulty. We believe that our assumptions about postlexical integration have been successful in this capacity, although we readily acknowledge that our assumptions are too simple to account for the full range of effects that stem from higher level, postlexical language processing. As the last simulation showed, the consequences of integration difficulty can be fairly rapid, influencing the probability of making refixations and thereby influencing the gaze duration on a word.

Recently, however, there have been some demonstrations that effects due to higher level, postlexical language processing can manifest even more rapidly than this, sometimes even influencing the duration of the initial fixation on a word (for a review, see Clifton et al., 2007). Some examples have come from experiments that examined how world knowledge affects language comprehension during reading (e.g., Warren \& McConnell, 2007). It is important to determine whether - and if so, how - the assumptions of E-Z Reader 10 can account for such findings. To make this determination, we used the model to simulate the results of an eye-movement experiment that examined how selectional restriction violations (i.e., vio- 
Table 3

Mean Observed (Warren \& McConnell, 2007) and Simulated (E-Z Reader 10) Effects of Plausibility and Selectional Restriction Violations on Target Words, in Milliseconds

\begin{tabular}{|c|c|c|c|c|c|c|}
\hline \multirow[b]{2}{*}{$\begin{array}{l}\text { Dependent } \\
\text { Measure }\end{array}$} & \multicolumn{3}{|c|}{ Observed } & \multicolumn{3}{|c|}{ Simulated } \\
\hline & $\begin{array}{l}\text { Possible-- } \\
\text { Plausible }\end{array}$ & $\begin{array}{l}\text { Possible- } \\
\text { Implausible }\end{array}$ & $\begin{array}{l}\text { Impossible- } \\
\text { Implausible }\end{array}$ & $\begin{array}{l}\text { Possible- } \\
\text { Plausible }\end{array}$ & $\begin{array}{l}\text { Possible- } \\
\text { Implausible }\end{array}$ & $\begin{array}{l}\text { Impossible- } \\
\text { Implausible }\end{array}$ \\
\hline First-fixation duration & 259 & 260 & 273 & 261 & 265 & 270 \\
\hline Gaze duration & 308 & 325 & 322 & 316 & 335 & 345 \\
\hline Total viewing time & 360 & 402 & 433 & 359 & 402 & 422 \\
\hline Probability regression out & .079 & .108 & .111 & .073 & .141 & .176 \\
\hline
\end{tabular}

Note-For nontarget words, $t(\mathrm{I})=25 \mathrm{msec} ; p_{\mathrm{F}}=0.13 ; p_{\mathrm{N}}=0.21$. For target words, $t(\mathrm{I})=34 \mathrm{msec} ; p_{\mathrm{F}}=0.13$ (possible-plausible) versus 0.31 (possible-implausible) versus 0.41 (impossible-implausible); $p_{\mathrm{N}}=0.21$.

lations of the semantic constraints a predicate places on its argument) influence readers' eye movements (Warren \& McConnell, 2007).

In the experiment, we tested three conditions defined by whether the situation described in the sentence was (1) possible and plausible; (2) possible but implausible; or (3) impossible, due to a selectional restriction violation, and implausible. Example sentences for each of the three conditions follow:

1. Possible-plausible: "The man used a strainer to drain the thin spaghetti. ..."

2. Possible-implausible: "The man used a blow-dryer to dry the thin spaghetti. ..."

3. Impossible-implausible: "The man used a photo to blackmail the thin spaghetti. ..."

Table 3 shows the key results of the Warren and McConnell (2007) experiment. The table shows four dependent measures on the target nouns, the first position where violations are evident (spaghetti, in the example sentences above). As the table indicates, the effect of implausibility, as evidenced by the comparison between the possibleimplausible condition and the possible-plausible condition, did not appear in first-fixation durations, but was evident in gaze duration and total viewing time. The probability of making a regression out of the critical noun was also inflated in the possible-implausible condition. This pattern of results suggests that readers detect implausibility relatively late, perhaps only when attempting to update their discourse model.

This pattern contrasts with the one associated with violations of possibility, in which effects appeared very early. Comparing the two implausible conditions, it is clear that possibility violations lengthened the duration of the first fixation on the target nouns. This suggests that such violations are detected very early, affecting the decision about when to move the eyes off the nouns. Within the framework of previous versions of the E-Z Reader model, this result would seemingly necessitate that an extremely strong violation of the semantic fit of a word with its context can slow the first stage of lexical processing, $\mathrm{L}_{1}$, on that word. However, in the context of our present assumptions, this result can be explained by assuming that postlexical integration is more likely to fail on the target noun in the impossible than in the possible conditions.

To simulate the three conditions of the Warren and McConnell (2007) experiment, we again used the Schilling et al. (1998) corpus sentences as frames. The target nouns (word $n$ ) and the words immediately before (word $n-1$ ) and after (word $n+1$ ) these words were then embedded within these frames in exactly the same manner as in the previous simulation. Because the cloze predictabilities of these critical words were unknown, but the majority of the words before and after the critical nouns were function words, the predictabilities of words $n-1, n$, and $n+1$ were set equal to $0.5,0$, and 0.5 , respectively. As with the prior simulation, the qualitative pattern of the simulation results was not dependent on these assumptions about predictability.

Our specific assumptions about postlexical processing were as follows: First, the overall base-rate of integration difficulty was made to be nonzero by setting the integration parameters to $t(\mathrm{I})=25 \mathrm{msec}$ and $p_{\mathrm{F}}=0.13$, for all nontarget words. The effects of target-word possibility and plausibility were then instantiated by increasing the integration time for target words to $t(\mathrm{I})=34 \mathrm{msec}$, and increasing the probability of rapid integration failure for these words to a degree concordant with the severity of the possibility-plausibility violation: (1) for possibleplausible target words, $p_{\mathrm{F}}=0.13$ (i.e., the base-rate value); (2) for possible-implausible target words, $p_{\mathrm{F}}=0.31$; and (3) for impossible-implausible target words, $p_{\mathrm{F}}=0.41$. The probability of regressing back to the source of integration difficulty was set equal to $p_{\mathrm{N}}=0.21$ for all words. With this value of $p_{\mathrm{N}}$, most interword regressions were directed back to locations before the point at which integration difficulty was detected. The results of this simulation are shown in Table 3.

As Table 3 shows, the model was able to simulate the correct pattern of results. In the possible-implausible condition, the violation of plausibility showed up relatively late, inflating gaze durations and total viewing times, but only modestly increasing (by $4 \mathrm{msec}$ ) the mean firstfixation durations. This type of violation also resulted in more regressions out of the critical nouns, consistent with what was observed in Warren and McConnell (2007). In the impossible-implausible condition, the violation of possibility had a more rapid effect, inflating the durations of all of the fixation measures, and again increasing the number of regressions out of the critical nouns. These patterns are also consistent with what was observed, and are important for at least two reasons: First, the fact that the model was able to account for the basic pattern of results 
Table 4

Mean Observed (Frazier \& Rayner, 1982) and Simulated (E-Z Reader 10) Fixation Durations, in Milliseconds, Immediately Prior to and After Fixating the Disambiguating Region for Three Sentence Types

\begin{tabular}{|c|c|c|c|c|c|c|c|c|}
\hline \multirow[b]{2}{*}{$\begin{array}{l}\text { Sentence } \\
\text { Type }\end{array}$} & \multicolumn{4}{|c|}{ Observed } & \multicolumn{4}{|c|}{ Simulated } \\
\hline & $\begin{array}{c}\text { Last } \\
\text { Fix. } \\
\text { Prior } \\
\text { To }\end{array}$ & $\begin{array}{l}\text { First } \\
\text { Fix. } \\
\text { After }\end{array}$ & Diff. & $\begin{array}{c}\text { Prob. } \\
\text { Regression } \\
\text { Into } \\
\text { Ambiguity }\end{array}$ & $\begin{array}{c}\text { Last } \\
\text { Fix. } \\
\text { Prior } \\
\text { To }\end{array}$ & $\begin{array}{l}\text { First } \\
\text { Fix. } \\
\text { After }\end{array}$ & Diff. & $\begin{array}{c}\text { Prob. } \\
\text { Regression } \\
\text { Into } \\
\text { Ambiguity } \\
\end{array}$ \\
\hline Late closure & 243 & 268 & -25 & 0.30 & $\begin{array}{l}228 \\
(232)\end{array}$ & $\begin{array}{c}237 \\
(250)\end{array}$ & $\begin{array}{c}-9 \\
(-18)\end{array}$ & $\begin{array}{c}0.20 \\
(0.20)\end{array}$ \\
\hline Early closure & 245 & 283 & -38 & 0.38 & $\begin{array}{c}230 \\
(232)\end{array}$ & $\begin{array}{c}247 \\
(262)\end{array}$ & $\begin{array}{c}-17 \\
(-30)\end{array}$ & $\begin{array}{c}0.27 \\
(0.27)\end{array}$ \\
\hline Nonminimal attachment & 226 & 292 & -66 & 0.33 & $\begin{array}{l}246 \\
(249)\end{array}$ & $\begin{array}{c}264 \\
(285)\end{array}$ & $\begin{array}{l}-18 \\
(-36)\end{array}$ & $\begin{array}{c}0.28 \\
(0.27)\end{array}$ \\
\hline
\end{tabular}

Note-For nondisambiguating words, $t(\mathrm{I})=25 \mathrm{msec} ; p_{\mathrm{F}}=0.11 ; p_{\mathrm{N}}=0.71$. For disambiguating words $t(\mathrm{I})=$ $66 \mathrm{msec} ; p_{\mathrm{F}}=0.70$ (late closure) versus 1.0 (early closure) versus 1.0 (nonminimal attachment); $p_{\mathrm{N}}=.71$. The simulated values shown in parentheses were obtained using an inhibition-of-return adjustment for $M_{1}$ set equal to $60 \mathrm{msec}$ (as opposed to $30 \mathrm{msec}$ ) for regressive saccades.

that were observed in the Warren and McConnell experiment suggests that the model's assumptions about postlexical processing are well founded and broadly applicable. Second, the simulation demonstrates how problems with postlexical processing, if they are detected rapidly enough, can affect even the earliest eye-movement measures on the word that is being processed. In our final simulation, we will demonstrate that the model can capture syntactic integration effects, as well as semantic ones, by simulating the results of Frazier and Rayner's (1982) classic experiment involving garden path sentences.

Frazier and Rayner (1982) provided evidence for the garden path theory of syntactic parsing by investigating readers' eye movements to temporarily ambiguous sentences that either did or did not violate the principles of minimal attachment and late closure. Table 4 shows two key results for a subset of the Frazier and Rayner conditions. The first of these results was that in the conditions involving integration difficulty (i.e., the early closure and nonminimal attachment sentences), the duration of the first fixation in the disambiguating region was longer than the duration of the last fixation in the ambiguous region. This indicates that disambiguating information becomes available to the reader very rapidly. The second key result was that there were many interword regressions from the disambiguating region back to the ambiguous region (which was the immediately preceding region), and this trend was more pronounced for the more-difficultto-process sentences. We hypothesized that an explanation of these results would require both a slowing down in postlexical processing and the occasional detection of postlexical processing difficulty.

Our simulation of the Frazier and Rayner (1982) experiments involved only a subset of their conditions - those involving the short variants of the sentences, and sentences involving late closure, early closure, and nonminimal attachment. The long variants of the sentences and the sentences involving minimal attachment were not simulated for two pragmatic reasons: First, the results that were observed with the longer sentences were qualitatively similar to those observed with the short sentences, but were based on analyses involving multiword regions that were less amenable to simulations (e.g., requiring information about more words). The second reason for including only a subset of the conditions is that the disambiguating region for the minimal attachment sentences occurred at the very ends of the sentences. Because lexical processing of the sentence-final words always ends abruptly in the model, the simulated eye-movement measures on these words are normally excluded from our analyses. We therefore decided to direct our efforts toward explaining the patterns of results that were observed with the short variants of the Frazier and Rayner sentences in three of their conditions - the relatively easy-to-process late-closure sentences, the more difficult-to-process early closure sentences, and the nonminimal-attachment sentences.

To simulate these results, the overall base-rate of integration difficulty was made to be nonzero by setting the integration parameters to $t(\mathrm{I})=25 \mathrm{msec}$ and $p_{\mathrm{F}}=0.11$ for all nondisambiguating words. The difficulty that was assumed to arise with the postlexical processing of the disambiguating words was then instantiated by increasing the integration time for disambiguating words to $t(\mathrm{I})=$ $66 \mathrm{msec}$, and increasing the probability of rapid integration failure for these words to $p_{\mathrm{F}}=0.7$ for the easierto-process late-closure sentences and to $p_{\mathrm{F}}=1$ for the more difficult-to-process early-closure and nonminimalattachment sentences. Finally, the probability of regressing back to the source of integration difficulty (i.e., the word where the difficulty associated with postlexical processing was assumed to be first noticed by the reader) was set equal to $p_{\mathrm{N}}=0.11$ for all words.

As Table 4 shows, the model can capture the key observed results: The durations of the first fixation in the disambiguating region is longer than the last fixation duration in the ambiguous region, there are a large number of interword regressions back to the ambiguous region, and both of these trends are much more pronounced for the two difficult conditions (early closure and nonminimal attachment) than for the easy condition (late closure). The model tends to underpredict both the absolute durations of the fixations and the relative differences between 
the two fixation durations of interest, but we contend that neither of these shortcomings is fatal. One reason for our conviction here is that the simulations were completed using the standard (default) parameter values that were used in all of the preceding simulations. Because the Frazier and Rayner (1982) experiment involved different materials and different participants, our approach of using the standard parameter values was very conservative. We would therefore argue that given these constraints, the relatively close correspondence between the observed and the simulated results is somewhat remarkable. The second reason for our conviction is related to the first: The correspondence between the observed and simulated values can be improved by adjusting the model's parameters. This is demonstrated in Table 4; the simulated values that are shown in parentheses were obtained by increasing the amount of additional time required for programming regressive saccades from $30 \mathrm{msec}$ (the value used in all of the other simulations reported in this article) to $60 \mathrm{msec}$. As Table 4 shows, the adjustment of this single parameter is sufficient to increase both the absolute durations of the fixations and the size of the differences between the pre- and postdisambiguating fixations. With this final demonstration, we now turn to a discussion of our model and what it indicates about the relationship between postlexical processing and other influences on eye movements during reading.

\section{DISCUSSION}

The simulations reported in this article are important because they show how, within the framework of a computational model of eye-movement control, the systems responsible for higher level, postlexical language processing might interact with those responsible for identifying words, focusing and shifting attention, and programming and executing saccades, in order to produce the patterns of eye movements observed during reading. Although one could quibble with any of our specific assumptions about the nature of these interactions, we contend that our demonstration provides an existence proof that postlexical processing can lag behind ongoing lexical processing, often generating no discernable effects on the progression of the eyes through the text, but that difficulty associated with postlexical processing will occasionally manifest very rapidly in the form of pauses and/or regressions back to the location where processing difficulty was first encountered. Our assumptions stipulate that such difficulty can arise whenever the postlexical processing of a word fails to complete in a timely manner (i.e., before the next word has been identified) or whenever it results in a severe syntactic or semantic violation (Frazier \& Rayner, 1982; Warren \& McConnell, 2007). Our assumptions also stipulate that the availability of one important source of information that is used to identify words - the degree to which a word is predicted in its sentential context - is contingent on the successful completion of postlexical processing.

Of course, it is possible that postlexical processing interacts with lexical processing or affects the forward move- ments of the eyes in some other, perhaps more complex, manner. For example, one could argue that postlexical processing interacts with lexical processing much more rapidly and directly, perhaps with both types of processing providing a set of soft constraints on the final representation for a sentence (MacDonald, Pearlmutter, \& Seidenberg, 1994; McRae, Spivey-Knowlton, \& Tanenhaus, 1998; Tabor, Juliano, \& Tanenhaus, 1997). Although our simulations do not preclude such a possibility, they do indicate that a small set of simple assumptions can explain a variety of important findings related to the effects of postlexical processing on eye movements during reading. We therefore contend that our approach has two important advantages over these other possible approaches: The first is that by implementing our assumptions about postlexical processing within the more general framework of a model of eye-movement control, we are able to make direct predictions about the patterns of eye movements that are observed in eyemovement experiments. That is to say, our model makes predictions about the actual time (in milliseconds) that is required for processing real linguistic units (e.g., words), rather than making predictions about, for example, the number of processing cycles required for processing large, multiword sentence regions (McRae et al., 1998; Spivey \& Tanenhaus, 1998; Tabor et al., 1997). The second advantage of our approach is its conceptual transparency: Each component in our model is described by a distinct processing module (Fodor, 1983) whose operating characteristics can, in principle, be studied and described independently of the other components. ${ }^{5}$ The alternative approaches have tended to be much more interactive in nature, making the inner workings of the models more opaque and, therefore, less useful as heuristic devices for thinking about what happens in the minds of readers or for making predictions about the outcomes of experiments (for an in-depth discussion of these issues, see Rayner et al., 2003).

One could argue that this comparison is unfair, because previous attempts to model the cognitive processes necessary for readers to understand sentences have focused on explaining the processes and representations underlying language processing, rather than investigating how this processing is related to the systems that are responsible for word identification, attention, and eye-movement control. We acknowledge this; also note that we are not suggesting that these alternative attempts to model sentence processing have not been useful. The main point we are trying to make is more modest - that our understanding of both sentence processing and eye-movement control might benefit from considering how these two areas of inquiry mutually constrain each other. This position is congruent with Newell's (1990) argument about the usefulness of developing cognitive architectures over developing single, task-specific models. We see our model as being akin to attempts to describe the cognitive architecture in that, by modeling the task of reading, we are trying to formally describe "very many of the most intricate workings of the human mind" (Huey, 1908, p. 6). With the inclusion of a stage of postlexical language processing, our model provides the rough outlines of the cognitive architecture that is necessary for the task of reading. 
The points that we have attempted to make thus far have been quite general, in the sense that not one of them is specific to the E-Z Reader model and might thus apply equally well to other models of eye-movement control (e.g., SWIFT; Engbert et al., 2005). That is not to say that the simulations reported in this article have no immediate implications for either the E-Z Reader model or the ongoing debate about whether E-Z Reader or some other model more accurately describes the perceptual, cognitive, and motor processes that guide eye movements during reading. We will now discuss a few of these more specific implications.

First, our new assumptions about attention and postlexical integration are important, because they demonstrate that the inclusion of these processes does not prevent the model from explaining the types of data that it was designed to explain. This point is not trivial because of the criticism of previous versions of the model (Inhoff et al., 2006; Radach et al., 2003; Radach et al., 2007), but because the time required to shift attention from one word to the next was assumed to be instantaneous. Similarly, the model has been criticized (Liversedge \& White, 2003; Murray, 2003; Perea \& Carreiras, 2003; Raney, 2003) because it was viewed as making no provisions for explaining how the processing of higher level language affects and is affected by lexical processing and eye-movement control. The simulations reported in this article address these criticisms and furthermore indicate that relatively simple assumptions about attention and postlexical processing allow the model to explain several findings that have heretofore been ignored by models of eye-movement control during reading. This point is important because, until now, the debate about which is the "best" model of eye-movement control has been focused largely on which model provides the most accurate or comprehensive account of relatively low-level variables (e.g., fixation landing-site distributions; Reilly \& O'Regan, 1998) and has largely ignored the equally important effects of the types of higher level variables (e.g., clause boundaries; Rayner et al., 2000) that were examined in the present article. We predict that consideration of these higher level variables will prove to be important diagnostic criteria for evaluating future models of eye-movement control in reading.

A second, related implication of our simulations has to do with the debate about the etiology of regressive saccades. In the current literature, there is some debate about the degree to which readers can accurately direct their gaze back to the source of processing difficulty; although there is some evidence suggesting that readers can accurately make long-distance regressions (Frazier \& Rayner, 1982; Kennedy et al., 2003; Kennedy \& Murray, 1987), there is also some evidence suggesting that readers initially make short, one-word or two-word regressions and then move their eyes back further, as necessary (Apel et al., 2007; Mitchell, Shen, Green, \& Hodgson, 2008).

Although our assumptions regarding regressions are agnostic with respect to which of these two characterizations of regressions is more correct, the model is clearly not sufficient to provide any type of detailed account of long- distance regressions. As we have already mentioned, if one could imagine the replacement of our simple assumptions about integration and regression by a detailed theory of language processing, how language processing fails, and the specific types of repair processes that are used to overcome such failures, then one might hope to have a detailed account of both long- and short-distance regressions. Barring this, our assumptions are capable of explaining only when regressions occur and - to a much more limited degree-whether the regressions will be directed back to the location where integration difficulty is first noticed by the reader (i.e., the word at which integration fails), or to earlier locations in the sentence (i.e., the word immediately before the source of integration difficulty).

Another important issue having to do with regressions concerns why they occur. If one accepts the assertion (Vitu, 2005; Vitu \& McConkie, 2000) that all interword regressive saccades are due to oculomotor error, difficulty associated with the identification of words, or difficulty associated with postlexical language processing, then it is interesting that the two most fully developed models of eye movements, E-Z Reader and SWIFT (Engbert et al., 2005), make very different assumptions about the causes of regressions. In E-Z Reader, the majority of regressions are due to difficulty with postlexical processing, with only a very small minority (typically less than $1 \%$ ) of additional regressions being due to oculomotor error, and no regressions being due to lexical processing difficulty per se. In contrast, in the SWIFT model, the majority of regressions are due to difficulty with lexical processing, with some smaller percentage being due to oculomotor error and none being due to postlexical processing. Given these differences, one could ask whether either or both models would overpredict the absolute number of regressions if each one included all three sources of regressions. For example, would the E-Z Reader model predict too many regressions if it assumed that problems with lexical processing could generate regressions? We would argue that because word identification problems are likely to manifest or be detected during postlexical integration (e.g., when the meaning of a misperceived word cannot be integrated into the overall meaning of the sentence; Pollatsek et al., 2008), the failure to include regressions that are due to difficulty associated with word identification is less problematic than the failure to include regressions that are due to integration difficulty. However, it is clear that further research will be needed to determine the precise reasons why interword regressions occur during reading. This future work is likely to benefit from the formulation of hypotheses about regressions (and other effects related to language processing) within the frameworks of computational models.

Another implication of our simulations also has to do with the specific assumptions of E-Z Reader versus those of SWIFT (Engbert et al., 2005) regarding the relative time course of lexical versus postlexical processing. According to the E-Z Reader model, words are (on average) identified after $150-250 \mathrm{msec}$ of processing, whereas the minimal postlexical processing that is necessary for inte- 
grating their meanings into the sentence representation is completed shortly thereafter (on average, $25 \mathrm{msec}$ later). Both stages of processing are hypothesized to have rapid effects on eye movements; the completion of the first stage of lexical processing is like "stepping on the gas," moving the eyes to the next word, whereas the completion of integration is like a decision not to "step on the brakes," so that the eyes continue their forward movement. Both of these assumptions contrast with those of the SWIFT model, where an autonomous random timer provides the signal to move the eyes forward, with processing difficulty of the previously fixated word occasionally intervening to inhibit or delay the onset of the saccades that otherwise move the eyes to new viewing locations. According to SWIFT, this saccade inhibition occurs with some delay (after $376 \mathrm{msec}$, on average). Note that both models predict that linguistic processes can inhibit the forward progression of the eyes; but in SWIFT, this is accomplished by lexical processing, whereas in E-Z Reader, it is accomplished by postlexical processing. This comparison raises the possibility that the relatively late inhibitory effects that SWIFT attributes to difficulty with lexical processing are more accurately described as reflecting postlexical processing. Although evidence for lagged effects of lexical processing has been reported in analyses of eye-movement corpora (Kliegl, Nuthmann, \& Engbert, 2006), these results are open to multiple interpretations (Rayner, Pollatsek, Drieghe, Slattery, \& Reichle, 2006), making future work (perhaps using brain-imaging methods; see, e.g., Reichle, Tokowicz, Liu, \& Perfetti, 2008) important for resolving this issue.

Another implication of our simulations is related to a contrast between the assumptions of E-Z Reader versus those of SWIFT, regarding how attention is allocated during reading. Within all versions of E-Z Reader, attention is allocated in a serial manner, with the "spotlight" of attention corresponding to ongoing lexical processing. Given that postlexical and lexical processing can simultaneously proceed on adjacent words in the current version of the model, the question arises about whether this necessitates some degree of parallelism in attention allocation, making the model's assumptions about attention more similar to those of SWIFT. If higher level language processes require attention, some limited parallelism would be necessary. However, there is still strict seriality within levels of representation in the current version of E-Z Reader, with lexical processing, as well as postlexical processing, proceeding one word at a time. This means that E-Z Reader never accesses the meanings of words out of order. In the SWIFT model, which allows parallel lexical processing, word $n+1$ can be identified before word $n$, necessitating either that words be integrated into a higher level representation out of order or that they be maintained in some type of buffer until the meanings of earlier words become available. Related to this question of attention allocation is the issue of how to characterize the attention and/or memory resources used during lexical and postlexical processing; for example, is there one pool of resources divided between the two, or are there separate resources for each (see, e.g., Caplan
\& Waters, 1999)? We prefer to remain agnostic about this important issue, but we acknowledge that future work may force us to adopt one position or the other.

In closing, let us briefly address a potential critique of the new assumptions of this model - the fact that they increase the model's complexity. This is true, but it is important to bear in mind that this added complexity is fairly minimal, considering that the new model's assumptions provide a framework for thinking about a theoretical domain that has been largely ignored by models of eye-movement control (see Reichle et al., 2003) and that has only been superficially addressed by language-processing models that make predictions about reading behavior (McRae et al., 1998; Spivey \& Tanenhaus, 1998; Tabor et al., 1997). Although one might argue that the added complexity reduces the model's conceptual transparency, making it less useful for generating and evaluating empirical predictions, it is important to bear in mind that conceptual transparency is relative, and that our model, with its new assumptions, is still simpler than many of the alternative models of eyemovement control (e.g., SWIFT; Engbert et al., 2005) that say little or nothing about higher level language processing, and simpler than the constraint-satisfaction models of language processing (McRae et al., 1998; Spivey \& Tanenhaus, 1998; Tabor et al., 1997) that are less transparent, by virtue of their highly interactive nature. Thus, although we acknowledge that E-Z Reader 10 may not be as simple as its predecessors, we suspect that its enhanced theoretical scope and its relative conceptual transparency will make it-like its predecessors (see, e.g., Reingold \& Rayner, 2006) - a useful heuristic for generating new research and enhancing our understanding of the cognitive processes that operate during reading.

\section{AUTHOR NOTE}

Preliminary parts of this work were presented at the 2008 CUNY Conference on Human Sentence Processing in Chapel Hill, NC. This work was supported by NIH R01 Grant HD053639, which was awarded to the first and second authors, and NIH R03 Grant HD048990 to the second author. Portions of this work were also completed while the first author was a fellow at the Hanse-Wissenschaftskolleg in Delmenhorst, Germany. The work described in this article benefited from discussions with Fernanda Ferreira, Don Mitchell, Alexander Pollatsek, Keith Rayner, and Adrian Staub. We also thank Albrecht Inhoff, Sébastian Milliet, and one anonymous reviewer for their very helpful comments on an earlier version of this article. An executable version of E-Z Reader 10, written in Java 5.0, is available at www.pitt.edu/ reichle/. Correspondence concerning this article should be addressed to E. D. Reichle, University of Pittsburgh, 635 LRDC, 3939 O'Hara St., Pittsburgh, PA 15260 (e-mail: reichle@pitt.edu).

\section{REFERENCES}

Apel, J., Henderson, J. M., \& Ferreira, F. (2007, August). Targeting regressions: Do people pay attention to the left? Poster presented at the 13th Annual Conference on Architectures and Mechanisms for Language Processing, Turku, Finland.

BAdDeley, A. D. (1986). Working memory. Oxford: Oxford University Press.

Balota, D. A., Pollatsek, A., \& Rayner, K. (1985). The interaction of contextual constraints and parafoveal visual information in reading. Cognitive Psychology, 17, 364-390.

CAPLAN, D., \& Waters, G. S. (1999). Verbal working memory and sentence comprehension. Behavioral \& Brain Sciences, 22, 77-94. 
Carpenter, R. H. S. (2000). The neural control of looking. Current Biology, 10, R291-R293.

ClaRK, V. P., FAN, S., \& Hillyard, S. A. (1995). Identification of early visual evoked potential generators by retinotopic and topographic analyses. Human Brain Mapping, 2, 170-187.

Clifton, C., Jr., Staub, A., \& Rayner, K. (2007). Eye movements in reading words and sentences. In R. P. G. van Gompel, M. H. Fischer, W. S. Murray, \& R. L. Hill (Eds.), Eye movements: A window on mind and brain (pp. 341-371). Amsterdam: Elsevier, North-Holland.

Egeth, H. E., \& Yantis, S. (1997). Visual attention: Control, representation, and time course. Annual Review of Psychology, 48, 269-297.

EHRLICH, S. F., \& RAYNER, K. (1981). Contextual effects on word perception and eye movements during reading. Journal of Verbal Learning \& Verbal Behavior, 20, 641-655.

Engbert, R., Nuthmann, A., Richter, E., \& Kliegl, R. (2005). SWIFT: A dynamical model of saccade generation during reading. Psychological Review, 112, 777-813.

ERIKSEn, C. W., \& Schultz, D. W. (1977). Retinal locus and acuity in visual information processing. Bulletin of the Psychonomic Society, 9, 81-84

FENG, G. (2006). Eye movements as time-series random variables: A stochastic model of eye movement control in reading. Cognitive Systems Research, 7, 70-95.

Fodor, J. A. (1983). The modularity of mind. Cambridge, MA: MIT Press.

Foxe, J. J., \& Simpson, G. V. (2002). Flow of activation from V1 to frontal cortex in humans: A framework for defining "early" visual processing. Experimental Brain Research, 142, 139-150.

Ferreira, F., Bailey, K. G. D., \& Ferraro, V. (2002). Good-enough representations in language comprehension. Current Directions in Psychological Science, 11, 11-15.

Ferreira, F., \& Patson, N. D. (2007). The "good enough" approach to language comprehension. Language \& Linguistics Compass, $\mathbf{1}$, 71-83.

Francis, W. N., \& KuČERA, H. (1982). Frequency analysis of English usage: Lexicon and grammar. Boston: Houghton Mifflin.

Frazier, L. (1998). Getting there (slowly). Journal of Psycholinguistic Research, 27, 123-146.

FraZier, L., \& RAYNER, K. (1982). Making and correcting errors during sentence comprehension: Eye movements in the analysis of structurally ambiguous sentences. Cognitive Psychology, 14, 178-210.

GougH, P. B. (1972). One second of reading. In J. F. Kavanagh \& I. G. Mattingly (Eds.), Reading by ear and by eye: The relationship between speech and reading (pp. 331-358). Cambridge, MA: MIT Press.

Hill, R., \& Murray, W. S. (2000). Commas and spaces: Effects of punctuation on eye movements and sentence parsing. In A. Kennedy, R. Radach, D. Heller, \& J. Pynte (Eds.), Reading as a perceptual process (pp. 565-589). Amsterdam: Elsevier, North-Holland.

Hirotani, M., Frazier, L., \& Rayner, K. (2006). Punctuation and intonation effects on clause and sentence wrap-up: Evidence from eye movements. Journal of Memory \& Language, 54, 425-443.

Huey, E. B. (1908). The psychology and pedagogy of reading. New York: Macmillan.

HyÖNÄ, J., \& POllatsek, A. (1998). Reading Finnish compound words: Eye fixations are affected by component morphemes. Journal of Experimental Psychology: Human Perception \& Performance, 24, 16121627.

InHOFF, A. W., EITER, B. M., \& RadACh, R. (2005). Time course of linguistic information extraction from consecutive words during eye fixations in reading. Journal of Experimental Psychology: Human Perception \& Performance, 31, 979-995.

InHOFF, A. W., RADACH, R., \& EITER, B. M. (2006). Temporal overlap in the linguistic processing of successive words in reading: Reply to Pollatsek, Reichle, \& Rayner (2006). Journal of Experimental Psychology: Human Perception \& Performance, 32, 1490-1495.

InHOFF, A. W., \& RAYNER, K. (1986). Parafoveal word processing during eye fixations in reading: Effects of word frequency. Perception \& Psychophysics, 40, 431-439.

Jolicceur, P., Ullman, S., \& Mackay, M. (1983). Curve tracing: A possible basic operation in the perception of spatial relations. Memory \& Cognition, 14, 129-140.
Just, M. A., \& Carpenter, P. A. (1980). A theory of reading: From eye fixations to comprehension. Psychological Review, 87, 329-354.

Kennedy, A., Brooks, R., Flynn, L.-A., \& Prophet, C. (2003). The reader's spatial code. In J. Hyönä, R. Radach, \& H. Deubel (Eds.), The mind's eye: Cognitive and applied aspects of eye movement research (pp. 193-212). Amsterdam: Elsevier, North-Holland.

KenNedy, A., \& MurRay, W. S. (1987). Spatial coordinates and reading: Comments on Monk (1985). Quarterly Journal of Experimental Psychology, 39A, 649-656.

KinTSCH, W. (1988). The role of knowledge in discourse comprehension: A construction-integration model. Psychological Review, 95, 163-182.

Kliegl, R., Nuthmann, A., \& Engbert, R. (2006). Tracking the mind during reading: The influence of past, present, and future words on fixation durations. Journal of Experimental Psychology: General, 135, 12-35

Landauer, T. K., Foltz, P. W., \& Laham, D. (1998). An introduction to latent semantic analysis. Discourse Processes, 25, 259-284.

Liversedge, S. P., \& White, S. J. (2003). Psycholinguistic processes affect fixation durations and orthographic information affects fixation locations: Can E-Z Reader cope? Behavioral \& Brain Sciences, 26, 492-493.

MacDonald, M. C., Pearlmutter, N. J., \& Seidenberg, M. S. (1994). The lexical nature of syntactic ambiguity resolution. Psychological Review, 101, 676-703.

McCandliss, B. D., Cohen, L., \& Dehaene, S. (2003). The visual word form area: Expertise for reading in the fusiform gyrus. Trends in Cognitive Sciences, 7, 293-299.

McConkie, G. W., Kerr, P. W., Reddix, M. D., \& Zola, D. (1988). Eye movement control during reading: I. The location of initial fixations on words. Vision Research, 28, 1107-1118.

McConkie, G. W., \& Rayner, K. (1975). The span of the effective stimulus during a fixation in reading. Perception \& Psychophysics, 17, 578-586.

McConkie, G. W., Zola, D., Grimes, J., Kerr, P. W., Bryant, N. R., \& WolfF, P. M. (1991). Children's eye movements during reading. In J. F. Stein (Ed.), Vision and visual dyslexia (pp. 251-262). London: Macmillan.

McDonald, S. A., Carpenter, R. H. S., \& Shillcock, R. C. (2005). An anatomically constrained, stochastic model of eye movement control in reading. Psychological Review, 112, 814-840.

McRae, K., Spivey-Knowlton, M. J., \& Tanenhaus, M. K. (1998). Modeling the influence of thematic fit (and other constraints) in online sentence comprehension. Journal of Memory \& Language, 38, 283-312.

Miellet, S., Sparrow, L., \& Sereno, S. C. (2007). Word frequency and predictability effects in reading French: An evaluation of the E-Z Reader model. Psychonomic Bulletin \& Review, 14, 762-769.

Mitchell, D. C., Shen, X., Green, M. J., \& Hodgson, T. L. (2008). Accounting for regressive eye-movements in models of sentence processing: A reappraisal of the selective reanalysis hypothesis. Manuscript submitted for publication.

Mouchetant-Rostaing, Y., Giard, M.-H., Bentin, S., Aguera, P.-E., \& Pernier, J. (2000). Neurophysiological correlates of face gender processing in humans. European Journal of Neuroscience, 12, 303-310.

MurRaY, W. S. (2003). The eye-movement engine. Behavioral \& Brain Sciences, 26, 494-495.

Newell, A. (1990). Unified theories of cognition. Cambridge, MA: Harvard University Press.

O'Regan, J. K. (1981). The "convenient viewing location" hypothesis. In D. F. Fisher, R. A. Monty, \& J. W. Senders (Eds.), Eye movements: Cognition and visual perception (pp. 289-298). Hillsdale, NJ: Erlbaum.

O'Regan, J. K., \& LÉvy-Schoen, A. (1987). Eye-movement strategy and tactics in word recognition and reading. In M. Coltheart (Ed.), Attention and performance XII: The psychology of reading (pp. 363384). Hillsdale, NJ: Erlbaum.

Perea, M., \& Carreiras, M. (2003). Regressions and eye movements: Where and when. Behavioral \& Brain Sciences, 26, 497.

Pollatsek, A., HyönÄ, J., \& Bertram, R. (2000). The role of morphological constituents in reading Finnish compound words. Journal 
of Experimental Psychology: Human Perception \& Performance, 26, 820-833.

Pollatsek, A., Juhasz, B. J., Reichle, E. D., Machacek, D., \& RAYNER, K. (2008). Immediate and delayed effects of word frequency and word length on eye movements in reading: A delayed effect of word length. Journal of Experimental Psychology: Human Perception \& Performance, 34, 726-750.

Pollatsek, A., Reichle, E. D., \& Rayner, K. (2003). Modeling eye movements in reading: Extensions of the E-Z Reader model. In J. Hyönä, R. Radach, \& H. Deubel (Eds.), The mind's eye: Cognitive and applied aspects of eye movement research (pp. 361-390). Amsterdam: Elsevier.

Pollatsek, A., Reichle, E. D., \& Rayner, K. (2006a). Attention to one word at a time in reading is still a viable hypothesis: Rejoinder to Inhoff, Radach, and Eiter (2006). Journal of Experiment Psychology: Human Perception \& Performance, 32, 1496-1500.

Pollatsek, A., Reichle, E. D., \& Rayner, K. (2006b). Serial processing is consistent with the time course of linguistic information extraction from consecutive words during eye fixations in reading: A response to Inhoff, Eiter, and Radach (2005). Journal of Experimental Psychology: Human Perception \& Performance, 32, 1485-1489.

Pollatsek, A., Reichle, E. D., \& Rayner, K. (2006c). Tests of the E-Z Reader model: Exploring the interface between cognition and eye-movement control. Cognitive Psychology, 52, 1-56.

Posner, M. I. (1978). Chronometric explorations of mind. Hillsdale, NJ: Erlbaum.

Radach, R., Deubel, H., \& Heller, D. (2003). Attention, saccade programming, and the timing of eye-movement control. Behavioral \& Brain Sciences, 26, 497-498.

RADACH, R., REILly, R., \& INHOFF, A. W. (2007). Models of oculomotor control in reading: Toward a theoretical foundation of current debates. In R. P. G. van Gompel, M. F. Fischer, W. S. Murray, \& R. L. Hill (Eds.), Eye movements: A window on mind and brain (pp. 237-269). Amsterdam: Elsevier, North-Holland.

RANEY, G. E. (2003). E-Z Reader 7 provides a platform for explaining how low- and high-level linguistic processes influence eye movements. Behavioral \& Brain Sciences, 26, 498-499.

RAYNER, K. (1975). The perceptual span and peripheral cues in reading. Cognitive Psychology, 7, 65-81

RAYNER, K. (1977). Visual attention in reading: Eye movements reflect cognitive processes. Memory \& Cognition, 5, 443-448.

RAYNER, K. (1978). Eye movements in reading and information processing. Psychological Bulletin, 85, 618-660.

RAYNER, K. (1979). Eye movements and cognitive psychology: On-line computer approaches to studying visual information processing. Behavior Research Methods, Instruments, \& Computers, 11, 164-171.

RAYNER, K. (1998). Eye movements in reading and information processing: 20 years of research. Psychological Bulletin, 124, 372-422.

Rayner, K., Ashby, J., Pollatsek, A., \& Reichle, E. D. (2004). The effects of frequency and predictability on eye fixations in reading: Implications for the E-Z Reader model. Journal of Experimental Psychology: Human Perception \& Performance, 30, 720-732.

RaYNer, K., \& Duffy, S. A. (1986). Lexical complexity and fixation times in reading: Effects of word frequency, verb complexity, and lexical ambiguity. Memory \& Cognition, 14, 191-201.

Rayner, K., Juhasz, B., Ashby, J., \& Clifton, C., JR. (2003). Inhibition of saccade return in reading. Vision Research, 43, 1027-1034.

RAYNER, K., KAmbe, G., \& Duffy, S. A. (2000). The effect of clause wrap-up on eye movements during reading. Quarterly Journal of Experimental Psychology, 53A, 1061-1080.

Rayner, K., LI, X., \& Pollatsek, A. (2007). Extending the E-Z Reader model of eye movement control to Chinese readers. Cognitive Science, 31, 1021-1033.

RAYNER, K., \& MorRISON, R. M. (1981). Eye movements and identifying words in parafoveal vision. Bulletin of the Psychonomic Society, 17, 135-138.

Rayner, K., \& Pollatsek, A. (1989). The psychology of reading. Englewood Cliffs, NJ: Prentice-Hall.

Rayner, K., Pollatsek, A., Drieghe, D., Slattery, T. J., \& ReiCHLE, E. D. (2006). Tracking the mind during reading via eye movements: Comments on Kliegl, Nuthmann, and Engbert (2006). Journal of Experimental Psychology: General, 136, 520-529.
Rayner, K., Pollatsek, A., \& Reichle, E. D. (2003). Eye movements in reading: Models and data. Behavioral \& Brain Sciences, 26, 507-518.

Rayner, K., Reichle, E. D., Stroud, M. J., Williams, C. C., \& PolLATSEK, A. (2006). The effect of word frequency, word predictability, and font difficulty on the eye movements of young and older readers. Psychology \& Aging, 21, 448-465.

Rayner, K., Sereno, S. C., Morris, R. K., Schmauder, A. R., \& ClifTON, C. (1989). Eye movements and on-line language comprehension processes. Language \& Cognitive Processes, 4, SI21-SI49.

Rayner, K., Sereno, S. C., \& Raney, G. E. (1996). Eye movement control in reading: A comparison of two types of models. Journal of Experimental Psychology: Human Perception \& Performance, 22, 1188-1200.

RAYNer, K., \& WeLl, A. D. (1996). Effects of contextual constraint on eye movements in reading: A further examination. Psychonomic Bulletin \& Review, 3, 504-509.

Rayner, K., Well, A. D., Pollatsek, A., \& Bertera, J. H. (1982). The availability of useful information to the right of fixation during reading. Perception \& Psychophysics, 31, 537-550.

Reichle, E. D., Pollatsek, A., Fisher, D. L., \& Rayner, K. (1998). Toward a model of eye movement control in reading. Psychological Review, 105, 125-157.

Reichle, E. D., Pollatsek, A., \& Rayner, K. (2006). E-Z Reader: A cognitive-control, serial-attention model of eye-movement control during reading. Cognitive Systems Research, 7, 4-22.

Reichle, E. D., Pollatsek, A., \& Rayner, K. (2007). Modeling the effects of lexical ambiguity on eye movements during reading. In R. P. G. van Gompel, M. H. Fischer, W. S. Murray, \& R. L. Hill (Eds.), Eye movements: A window on mind and brain (pp. 271-292). Amsterdam: Elsevier, North-Holland.

Reichle, E. D., Rayner, K., \& Pollatsek, A. (1999). Eye movement control in reading: Accounting for initial fixation locations and refixations within the E-Z Reader model. Vision Research, 39, 4403-4411.

Reichle, E. D., Rayner, K., \& Pollatsek, A. (2003). The E-Z Reader model of eye movement control in reading: Comparisons to other models. Behavioral \& Brain Sciences, 26, 445-476.

Reichle, E. D., Tokowicz, N., Liu, Y., \& Perfetti, C. A. (2008). Testing an assumption of the E-Z Reader model of eye-movement control during reading: Using event-related potentials to examine the familiarity check. Manuscript submitted for publication.

ReILLY, R. G., \& O'REgAN, J. K. (1998). Eye movement control in reading: A simulation of some word-targeting strategies. Vision Research, 38, 303-317.

REILLY, R. G., \& RADACH, R. (2006). Some empirical tests of an interactive activation model of eye movement control in reading. Cognitive Systems Research, 7, 34-55.

ReINGOLD, E. M., \& RAYNER, K. (2006). Examining the word identification stages hypothesized by the E-Z Reader model. Psychological Science, 17, 742-746.

SANFord, A. J. (2002). Context, attention and depth of processing during interpretation. Mind \& Language, 17, 188-206.

SANFORD, A. J., \& GARROD, S. C. (2005). Memory-based approaches and beyond. Discourse Processes, 39, 205-224.

Schilling, H. E. H., Rayner, K., \& Chumbley, J. I. (1998). Comparing naming, lexical decision, and eye fixation times: Word frequency effects and individual differences. Memory \& Cognition, 26, 12701281.

Shulman, G. L., Remington, R. W., \& McLean, J. P. (1979). Moving attention through visual space. Journal of Experimental Psychology: Human Perception \& Performance, 5, 522-526.

Sparrow, L., Miellet, S., \& Coello, Y. (2003). The effects of frequency and predictability on eye fixations in reading: An evaluation of the E-Z Reader model. Behavioral \& Brain Sciences, 26, 503-505.

Spivey, M. J., \& Tanenhaus, M. K. (1998). Syntactic ambiguity resolution in discourse: Modeling the effects of referential context and lexical frequency. Journal of Experimental Psychology: Learning, Memory, \& Cognition, 24, 1521-1543.

Swets, B., Desmet, T., Clifton, C., Jr., \& Ferreira, F. (2008). Underspecification of syntactic ambiguities: Evidence from self-paced reading. Memory \& Cognition, 36, 201-216.

Tabor, W., Juliano, C., \& Tanenhaus, M. K. (1997). Parsing in a dynamical system: An attractor-based account of the interaction of 
lexical and structural constraints in sentence processing. Language \& Cognitive Processes, 12, 211-271.

TAFT, M. (1991). Reading and the mental lexicon. Hillsdale, NJ: Erlbaum.

Tsal, Y. (1983). Movements of attention across the visual field. Journal of Experimental Psychology: Human Perception \& Performance, 9, 523-530.

VAnRullen, R., \& Thorpe, S. J. (2001). The time course of visual processing: From early perception to decision-making. Journal of Cognitive Neuroscience, 13, 454-461.

VITU, F. (2005). Visual extraction processes and regressive saccades in reading. In G. Underwood (Ed.), Cognitive processes in eye guidance (pp. 1-32). Oxford: Oxford University Press.

Vitu, F., \& McConkIE, G. W. (2000). Regressive saccades and word perception in adult reading. In A. Kennedy, R. Radoch, D. Heller, \& J. Pynte (Eds.), Reading as a perceptual process (pp. 301-326). Amsterdam: Elsevier, North-Holland.

Vitu, F., McConkie, G. W., Kerr, P., \& O'Regan, J. K. (2001). Fixation location effects on fixation durations during reading: An inverted optimal viewing position effect. Vision Research, 41, 3511-3531.

WARREN, T., \& MCCONNELL, K. (2007). Investigating effects of selectional restriction violations and plausibility violation severity on eyemovements in reading. Psychonomic Bulletin \& Review, 14, 770-775.

WeGER, U. W., \& INHOFF, A. W. (2007). Long-range regressions to previously read words are guided by spatial and verbal memory. Memory \& Cognition, 35, 1293-1306.

YANG, S.-N. (2006). A oculomotor-based model of eye movements in reading: The competition/interaction model. Cognitive Systems Research, 7, 56-69.

\section{NOTES}

1. Although there are more sophisticated ways of operationally defining the degree to which a word's meaning is constrained by or predicted from its sentence context (e.g., latent semantic analysis; Landauer, Foltz, \& Laham, 1998), we used the cloze probabilities because this allowed us to directly compare the simulations reported in this article with earlier ones (which used the same cloze-task norms).
2. In eye-movement experiments like the ones that are simulated in the present article, each degree of visual angle typically corresponds to three to four character spaces.

3. This method has been used successfully on several occasions (Pollatsek et al., 2003, 2006b, 2006c; Rayner et al., 2004; Rayner, Reichle, et al., 2006; Reichle et al., 2007) in lieu of completing simulations using the actual sentence materials that were used in the various experiments. Doing the latter is prohibitively expensive, because it is first necessary to determine the frequency, length, and predictability of all of the words in the sentence corpus. Although frequencies and lengths are easy to determine, predictabilities can be determined only by completing a separate experiment to collect cloze-task probability norms. After this information has been obtained, it is then necessary to determine the model's best fitting parameter values. This is also a costly process: First, it is necessary to compute the mean first-fixation and gaze durations for each word in the corpus, as well as the mean probabilities of making one and two fixations on each word. These values are then used to calculate an index of the model's overall performance in simulating the observed data (e.g., the root-mean-square deviation, or RMSD, between the observed and predicted means), which can then be used in conjunction with a parametersearching heuristic to find the set of parameters that allows the model to most accurately simulate the observed data. For a detailed explanation of how this is done, see the appendix of Reichle et al. (1998).

4. To provide some basis for comparison, the previously published versions of E-Z Reader have had RSMDs ranging from 0.088 (Reichle et al., 2003 ) to 0.218 (Reichle, Rayner, \& Pollatsek, 1999). Generally speaking, RMSD values lower than 0.5 provide fits that are reasonably close to the observed means (see, e.g., Sparrow, Miellet, \& Coello, 2003).

5 . We readily acknowledge that we are taking a hard theoretical stance by adopting this type of modular (Fodor, 1983) architecture, and that this position may be incorrect. We would nevertheless argue that this position is tremendously useful, because it makes the model architecture more conceptually transparent and computationally tractable than the architectures of highly interactive (e.g., connectionist soft-constraint satisfaction; MacDonald et al., 1994) models.

(Manuscript received September 5, 2007; revision accepted for publication July 15, 2008.) 